\title{
Article
}

\section{Enhancing Biopharmaceutical Attributes of Phospholipid Complex-loaded Nanostructured Lipidic Carriers of Mangiferin: Systematic Development, Characterization and Evaluation}

Khurana, Rajneet Kaur, Bansal, Arvind, Beg, Sarwar, Burrow, Andrea Julie, Katare, O. P, Singh, Kamalinder K and Singh, Bhupinder

Available at http://clok.uclan.ac.uk/17291/

Khurana, Rajneet Kaur, Bansal, Arvind, Beg, Sarwar, Burrow, Andrea Julie, Katare, O. P, Singh, Kamalinder K ORCID: 0000-0001-7325-0711 and Singh, Bhupinder (2017) Enhancing Biopharmaceutical Attributes of Phospholipid Complex-loaded Nanostructured Lipidic Carriers of Mangiferin: Systematic Development, Characterization and Evaluation. International Journal of Pharmaceutics, 518 (1-2). pp. 289-306. ISSN 0378-5173

It is advisable to refer to the publisher's version if you intend to cite from the work. http://dx.doi.org/10.1016/j.ijpharm.2016.12.044

For more information about UCLan's research in this area go to http://www.uclan.ac.uk/researchgroups/ and search for < name of research Group >.

For information about Research generally at UCLan please go to http://www.uclan.ac.uk/research/

All outputs in CLoK are protected by Intellectual Property Rights law, including Copyright law. Copyright, IPR and Moral Rights for the works on this site are retained by the individual authors and/or other copyright owners. Terms and conditions for use of this material are defined in the policies page. 
Enhancing Biopharmaceutical Attributes of Phospholipid Complex-loaded

Nanostructured Lipidic Carriers of Mangiferin: Systematic Development,

\section{Characterization and Evaluation}

Rajneet Kaur Khurana1, Arvind Bansal'2, Sarwar Beg1, Andrea Julie Burrow ${ }^{3}$, OP Katare $^{1}$, Kamalinder K Singh ${ }^{3}$, Bhupinder Singh ${ }^{1,4^{*}}$

1UGC Centre of Advanced Studies, University Institute of Pharmaceutical Sciences, Panjab University, Chandigarh 160014, India

2Department of Pharmaceutics, National Institute of Pharmaceutical Education and Research (NIPER), S.A.S. Nagar, Punjab 160062, India

${ }^{3}$ School of Pharmacy and Biomedical Sciences, University of Central Lancashire, Preston, PR1 2HE, UK

${ }^{4}$ UGC-Centre of Excellence in Applications of Nanomaterials, Nanoparticles and Nanocomposites (Biomedical Sciences), Panjab University, Chandigarh 160014, India

*To whom correspondence should be addressed

Professor Bhupinder Singh Bhoop M Pharm, Ph D, D St

Chairman, University Institute of Pharmaceutical Sciences

Coordinator, UGC Centre of Advanced Studies

Coordinator, UGC Center for Excellence in Nano Applications

Panjab University, Chandigarh 160 014, India

E-mail: bsbhoop@yahoo.com, bsbhoop@pu.ac.in

푱 +91 172 2534103, Fax: +91 1722543101

\section{Abstract}


Mangiferin (Mgf), largely expressed out from the leaves and stem bark of Mango, is a potent antioxidant. However, its in vivo activity gets tremendously reduced owing to poor aqueous solubility and inconsistent gastrointestinal absorption, high hepatic first-pass metabolism and high P-gp efflux. The current research work, therefore, was undertaken to overcome the biopharmaceutical hiccups by developing the Mgfphospholipid complex (PLCs) loaded in nanostructured lipidic carriers (NLCs). The PLCs and NLCs were prepared using refluxing, solvent evaporation and hot emulsification technique, respectively with various molar ratios of $\mathrm{Mgf}$ and Phospholipon 90 G, i.e., 1:1; 1:2; and 1:3. The complex was evaluated for various physicochemical parameters like drug content (96.57\%), aqueous solubility (25-fold improved) and oil-water partition coefficient (10-fold enhanced). Diverse studies on the prepared complex using FTIR, DSC, PXRD and SEM studies ratified the formation of PLCs at 1:1 ratio. The PLCs were further incorporated onto NLCs, which were systematically optimized employing a face centered cubic design (FCCD), while evaluating for particle size, zeta potential, encapsulation efficiency and in vitro drug release as the CQAs. Caco-2 cell line indicated insignificant cytotoxicity, and P-gp efflux, bi-directional permeability model and in situ perfusion studies specified enhanced intestinal permeation parameters. In vivo pharmacokinetic studies revealed notable increase in the values of $C_{\max }(4.7$-fold) and AUC (2.1-fold), respectively, from PLCs-loaded NLCs vis-à-vis Mgf solution. In a nutshell, the promising results observed from the present research work signified boosted biopharmaceutical potential of the optimized PLCs-loaded NLCs for potentially augmenting the therapeutic efficacy of Mgf. 
Keywords: QbD, antioxidants, phytomolecule, molecular docking, P-gp efflux, Caco2 bidirectional permeability assay, SPIP

\section{Introduction}

Of late, mangiferin (Mgf), a polyphenolic C-glycoside has been gaining enormous recognition in pharmaceutical and food industries for its nutritional and therapeutic values. It possesses several pharmacological activities like antioxidant (Rodriguez et al., 2006), anti-inflammatory (Saha et al., 2016), anti-viral (Zheng and Lu, 1990), analgesic (Dar et al., 2005), immunomodulatory (Leiro et al., 2004; Sarkar et al., 2004), antidiabetic (Ojewole, 2005), besides other's. Amongst all these, the ability of Mgf to act as a potent antioxidant by scavenging free radicals is known to be of immense importance for preventing the potential DNA damage (Zhang, 2013) and for inhibiting the growth of cancer cells by inducing cellular apoptosis (Minglin et al., 2016; Takeda et al., 2016).

Despite being a potent phytomolecule, the use of Mgf is restricted due to its low and variable oral bioavailability (about 1.5 to $5.0 \%$ ), usually ascribed to its poor aqueous solubility (0.1 to $0.3 \mathrm{mg} / \mathrm{mL}$ ), low lipophilicity, high P-gp efflux, considerable first-pass metabolism and cytochrome P-450 mediated metabolism in gut enterocytes (Basheer and Kerem, 2015; Khurana et al., 2016). Besides, Mgf display rapid clearance from the body via glucuronidation of the hydroxyl groups present at position- 6 and 7 of its xanthone moiety, which, in turn, tends to reduce its potential antioxidant and anticancer activities, due to shorter half-life (van der Merwe et al., 2011). 
Mgf, till date, is marketed in the form of conventional tablets, along with other antioxidants. However, such formulations exhibit limited fruition for potentiating the desired therapeutic efficacy of Mgf owing to the aforementioned biopharmaceutical hiccups. A score of formulation strategies including solid dispersions (Qin et al., 2014), cyclodextrin inclusion complex (da Rocha Ferreira et al., 2013; Yang et al., 2013), crystal engineering and salt formation (Teng and $\mathrm{Wu}, 2012$ ), phospholipid complex (Ma et al., 2014) and spray-dried encapsulation (Souza et al., 2013) have already been reported in literature. These systems, however, have yielded limited improvement in the biopharmaceutical attributes of Mgf, plausibly owing to mere improvement in solubility and dissolution behavior. Keeping in view of the potential limitations of the existing formulation techniques, the development of newer and more effective formulation strategies for Mgf is highly called for.

The phospholipid systems, in this context, have lately been explored for enhancing the biopharmaceutical performance and therapeutic efficacy of bioactives with poor hydrophilicity and lipophilicity (Renukuntla et al., 2013). As phospholipids constitute a major part of the bio-membrane, these hold good biocompatibility and act as a carrier for delivering drugs across the biological barriers (Renukuntla et al., 2013). The amphiphilic nature of phospholipids tends to provide enhanced solubility and permeability of the drugs, thus improving their oral biopharmaceutical performance (Pichot et al., 2013). Other stellar merits of phospholipidic formulations include ease of preparation, along with high drug loading capacity and long-term stability. Several, literature reports suggest that incorporation of drug-phospholipid complexes into the nanostructured systems can further have remarkable increase in the 
biopharmaceutical performance of the drugs (Singh et al., 2012; Rawat et al., 2013; Xia et al., 2013).

The nanosystems composed of lipids not only enable the increased solubility and bioavailability of less soluble drugs, but also augment release and permeability of drugs, along with gastric protection against degradation from luminal enzymes (Renukuntla et al., 2013). Indeed, nanocarriers such as lipid micelles (Neuberg et al., 2015), solid lipid nanoparticles (Mukherjee et al., 2009; Bunjes, 2010), nanostructured lipidic carriers (NLCs) (Khan et al., 2015) and lipid nanocapsules (Sánchez-Moreno et al., 2012) have already been reported to hold immense promise for oral delivery of poorly water-soluble bioactives. Amongst these nanocarriers, the NLCs are considered to be of wider interest owing to their high drug-loading efficiency and drug stability (Naseri et al., 2015; Shah et al., 2016). Accordingly, the current work on the proposed novel technology was undertaken, wherein the PLCs of Mgf were incorporated into NLCs, for further enhancing the biopharmaceutical attributes. The nature of the intended research work on Mgf has not been reported in literature so far. The present research work, therefore, involves the investigation of dual formulation strategies involving the use of PLCs-loaded NLCs for improving the oral bioavailability of Mgf. In this regard, PLCs were prepared and extensively characterized through FTIR, DSC, PXRD, SEM, and molecular docking studies for confirming the formation of complex. Further, intestinal absorption and permeability studies on the developed formulations have been performed on Caco-2 bidirectional assay model. Subsequently, intestinal perfusion studies and pharmacokinetic studies 
were also performed on Sprague-Dawley (SD) rats for evaluating the improvement in permeability, bioavailability and absorption parameters.

\section{Materials and Methods}

Mgf was provided ex-gratis by International Association on Mangiferin Research (IAMR), Nanning, Guangxi, China. Phospholipon 90 G (PL) (soybean lecithin at 90\% of phosphatidylcholine) was provided as gift sample by M/s Phospholipon $\mathrm{GmbH}$, Germany. Labrafil M 2125 and Compritol 888 ATO were gifted by M/s Gattefosse, Cedex, France. All the solvents were procured from Merk Pvt. Ltd., India.

\subsection{Defining the quality target product profile (QTPP)}

As per the Quality by Design (QbD)-based approach of product development, QTPP was set-up not only for the development of NLCs of Mgf's PLCs but for improving the therapeutic performance for the patients benefit. The QTPP described for formulating NLCs of Mgf, include key quality characteristics like, dosage form type, nature, strength, route of administration, pharmacokinetic and stability requirements.

\subsection{Determining critical quality attributes (CQAs)}

Patient-centric CQAs include both physical and formulation attributes representing the out-standing features of NLCs as the target drug product. Among the several quality attributes, the prominent attributes critically influencing the product performance were selected for the purpose. The selected CQAs include particle size (i.e., essential for faster drug absorption), zeta potential (i.e., indicative of the stability of drug product), entrapment efficiency (i.e., indicative of the drug loading potential) and in vitro percent drug release (i.e., indicative of better absorption from gastrointestinal milieu). 


\subsection{Molecular modelling and simulation studies}

During complexation process, the role of the molecular modelling and simulation studies is to analyse and confirm the potential interactions between Mgf and PL. Chem Draw Ultra 12.0 software was utilized to draw the chemical structure of Mgf. Further, ChemBio 3D Pro-12.0 software (M/s Cambridgesoft, Cambridge, USA) was employed to generate the 3D model by minimizing the free energy. Docking studies were conducted between Mgf and analogue of phospholipid in the human body, i.e., phosphatidylcholine transfer protein using MGL tool (Autodock software version 1.5.6) (M/s GNU General Public Licence, CA, USA). For this, protein data bank, i.e.,

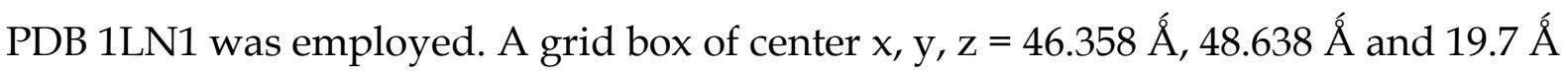
was created around Mgf to wrap it completely (Lee et al., 2013).

\subsection{Preparation of the Mangiferin's Phospholipid Complex (PLCS)}

Solvent-evaporation method was used for the preparation of PLCs as per the reported procedure (Ma et al., 2014). Briefly, the required amount of Mgf and PL in the stoichiometric ratio 1:1, 1:2 and 1:3 was dissolved in $100 \mathrm{~mL}$ of $80 \%$ ethanol by magnetic stirring at room temperature. The mixture was refluxed at $60^{\circ} \mathrm{C}$ temperature for $2 \mathrm{~h}$. The ethanol was evaporated at reduced pressure using rotary flask evaporator at $40{ }^{\circ} \mathrm{C}$. The resultant complex was collected and stored under dried condition in desiccators.

\subsection{Characterization of the prepared PLCs}

\subsubsection{Drug content determination}

The content of Mgf in the PLCs was determined by HPTLC method previously reported by us (Khurana et al., 2016). Accurately amount of pure Mgf and PLCs (10 mg each), were solubilised in methanol, and diluted simultaneously in the mobile 
phase before its application on the silica gel plate. Subsequently, densitometric scanning of Mgf was performed at $\lambda_{\max }$ of $262 \mathrm{~nm}$ at Camag TLC Scanner for quantifying the drug content through already reported and validated method by us (Khurana et al., 2016).

\subsubsection{Solubility studies and partition coefficient}

Excess of Mgf, physical mixture of Mgf and PL, and PLCs were dissolved in $5 \mathrm{~mL}$ of water and n-octanol. Each experiment was conducted in triplicate with continuous shaking in a shaker for $48 \mathrm{~h}$. Further, centrifugation was performed at 10,000 rpm $(5,590 \times \mathrm{g})$ for a period of $10 \mathrm{~min}$. HPTLC was employed to analyse the supernatant obtained after filtration $(0.22 \mu \mathrm{m})$ after apt dilutions.

\subsubsection{Powder X-Ray diffraction (PXRD)}

The PXRD studies were carried out on Mgf, PL, physical mixture and PLCs, where the diffraction patterns were recorded under ambient conditions on X-ray powder diffractometer (D8 Advance, Bruker, Karlsruhe, Germany) using Cu Ka radiation $\left(=1.54 \mathrm{~A}^{\circ}\right)$ at $40 \mathrm{kV}, 40 \mathrm{~mA}$ passed through nickel filter (Yang et al., 2013).

\subsubsection{Differential scanning calorimetry analysis (DSC)}

The DSC studies were carried out on 1-2 mg sample of Mgf, PL, their physical mixture, PLCs and PLCs-NLCs by DSC Q20 (M/s TA Instruments, Detroit, USA) in crimped aluminium pans, heated from 25 to $250{ }^{\circ} \mathrm{C}$ at a scanning rate of $10{ }^{\circ} \mathrm{C} / \mathrm{min}$ (Ma et al., 2014). 


\subsubsection{Fourier-transform infrared (FTIR) spectroscopy}

FTIR spectra of Mgf, PL, their physical mixture, PLCs and PLCs-NLCs were obtained using an FTIR-8300 spectrophotometer (Shimadzu, Japan) as per the procedure reported by Beg and associates (Beg et al., 2016).

\subsubsection{Scanning electron microscopy (SEM)}

In order to have better conceptualization and visualization, SEM (JEM-2100F (M/s Jeol, Tokyo, Japan) studies were performed on Mgf, PL, physical mixture and PLCs with instrument named. Mgf, PL, physical mixture and PLCs were coated with gold in a sputter coater and their surface morphology was viewed and photographed (Beg et al., 2016).

\subsection{Development of Nanostructured Lipidic Carriers (NLCs)}

\subsubsection{Risk assessment studies}

To identify the possible critical material attributes (CMAs) and/or critical process parameters (CPPs) affecting the critical quality attributes (CQAs), risk assessment studies were carried out by constructing Ishikawa fish-bone diagram, to delineate the potential cause-and-effect relationship among the product and process variables. Out of this diagram, key material attributes (MAs)/process parameters (PPs) were prioritized. Further, for qualitative analysis of low, medium and high-risk(s) related with each MAs and PPs, the risk estimation matrix (REM) was built.

\subsubsection{Screening of the lipids}

Various solid and liquid lipids were screened on the basis of their suitability for Mgf. Fixed quantity of the lipids were taken in the culture flasks and excess amount of Mgf was added to them. The solid lipids were allowed to melt at $80^{\circ} \mathrm{C}$ for $2 \mathrm{~h}$ using a 
thermostatically controlled water bath (M/s Rivera, Mumbai, India). On the other hand, the solubility studies for the liquid lipids were carried out at ambient temperature. After $48 \mathrm{~h}$, an aliquot $(100 \mu \mathrm{L})$ of the lipids was taken from the supernatant after centrifugation at 5,000 $\mathrm{rpm}(1,190 \times \mathrm{g})$, suitably diluted in 7:3 ratio mixtures of methanol and chloroform to solubilise Mgf, and filtered for analysis using previously validated and reported HPTLC method at a $\lambda_{\max }$ of $262 \mathrm{~nm}$ (Khurana et al., 2016).

\subsubsection{Preparation of the PLCs-NLCs}

The NLCs were prepared by hot emulsification and ultrasonication method. The oil phase, containing a mixture of solid and liquid lipids in the ratio of 90:10 and 70:30, was heated up to $80^{\circ} \mathrm{C}$, followed by addition of PLCs, and subsequently complete solubilization in the molten lipid phase. Simultaneously, the aqueous phase containing Tween 80 as surfactant and soy lecithin $(50 \mathrm{mg})$ as stabilizer were mixed in $10 \mathrm{~mL}$ of water and heated up to the identical temperature (Zhao et al., 2013). The ratio of lipid to aqueous phase was kept between 1:10. Using a Ultra-Turrax homogenizer fixed at 10,000 rpm $(5,590 \times \mathrm{g})$, the aqueous phase was mixed with the lipid phase for $30 \mathrm{~min}$. The formed emulsion was further ultra-sonicated using a probe sonicator. This ultra fine dispersion containing NLCs was cooled down in an ice bath and stored until use.

\subsubsection{Systematic development of the NLCs employing FCCD}

The most influential factors identified from REM were employed for systematic optimization using face centered cubic design (FCCD). A total of thirteen formulations were prepared as per the FCCD employing two factors, viz. solid lipid concentration 
$\left(X_{1}\right)$ and surfactant concentration $\left(X_{2}\right)$ at three levels of each, including low $(-1)$, medium (0) and high (+1) levels with quintuplicate studies conducted for the center point $(0,0)$ formulation. The CQAs selected for the prepared formulations include, particle size, zeta potential, encapsulation efficiency and drug release.

\subsection{Characterization of the prepared PLCs-NLCs}

\subsubsection{Particle size and zeta potential}

For particle size, polydispersity index (PDI) and zeta potential measurement, the NLCs prepared as per the experimental design were diluted 100-fold with distilled water employing Zetasizer ZS 90 instrument (M/s Malvern Instruments, Worcestershire, UK) based on dynamic light scattering technique.

\subsubsection{Entrapment efficiency}

As per the generated design matrix, entrapment efficiency of the NLCs-loaded with PLCs was determined by centrifuging the dispersion at $10,000 \mathrm{rpm}(5,590 \times \mathrm{g})$. The obtained pellet was made to digest by Triton-X-100 $(0.1 \% \mathrm{w} / \mathrm{v})$, followed by ultrasonication for $15 \mathrm{~min}$ to completely remove the drug from nanostructured systems (Zhao et al., 2013). Mgf was extracted in methanol and filtered $(0.45 \mu \mathrm{m})$ to obtain a fine dispersion. The amount of drug entrapped was quantified employing a previously developed, validated and reported HPTLC method (Khurana et al., 2016). Eq. 1 was employed to calculate the entrapment efficiency, as follows:

$$
\text { Encapsulation efficiency }=\frac{D_{1}-D_{2}}{D_{2}} \times 100 \quad \ldots \text { Eq. } 1
$$

where, $\mathrm{D}_{1}$; amount of drug added and $\mathrm{D}_{2}$; unentrapped drug

\subsubsection{In vitro drug release studies}


Dialysis bag method was employed to study in vitro drug release behaviour from PLCs-NLCs, in $250 \mathrm{~mL}$ of $0.1 \mathrm{~N} \mathrm{HCl}(\mathrm{pH} 1.2)$ for first $2 \mathrm{~h}$, followed by phosphate buffer (pH 6.8) up to $24 \mathrm{~h}$ at $37 \pm 0.5^{\circ} \mathrm{C} ; 100 \mathrm{rpm}$. The PLCs-NLCs, equivalent to $10 \mathrm{mg}$ was placed in the dialysis bag, and $5 \mathrm{~mL}$ of sample was withdrawn at defined time intervals. In order to maintain the sink conditions, replenishment with an equal volume of fresh dissolution media was done.

\subsubsection{Transmission electron microscopy (TEM)}

An aliquot of $1 \mathrm{~mL}$ of the optimized PLCs-NLCs formulations were diluted in $250 \mathrm{~mL} 0.1 \mathrm{~N}$ $\mathrm{HCl}$ and used for TEM analysis. A drop of the sample was placed on copper grids, stained with $1 \%$ phosphotungstic acid solution for 30 s, and visualized under electron microscope (JEM-2100 F, M/s Jeol, Tokyo, Japan) (Beg et al., 2015).

\subsubsection{Mathematical modelling and optimization data analysis}

Multiple linear regression analysis (MLRA) with second-order quadratic polynomial models was employed to carry out DoE-based optimization data analysis. Moreover, suitability of the selected mathematical model was analyzed using various diagnostic plots. To understand the relationship amongst various CQAs, CMAs and CPPs, response surface analysis was conducted employing 3D-reposne surface plots (Singh et al., 2016).

\subsubsection{Search for the optimum formulation and validation studies}

Initially, a feasible region was located by assigning the desirable values for each of the CQAs, followed by narrowing down the constraints to predict the optimum solutions. Numerical optimization also helps in choosing the best solution with desirability 
closer to one. Further, design space within the overlay plot also demarcates the optimized formulation (Singh et al., 2005).

\subsection{Caco-2 cell line studies}

\subsubsection{Caco-2 cell culture}

Caco-2 cell line, Caucasian colon adenocarcinoma (cell passages between 40 to 55), was procured from European Collection of Authenticated Cell Cultures (ECACC), Public Health England, Salisbury, England. Cells were grown in EMEM media containing $2 \mathrm{mM}$ glutamine, 1\% (v/v) non-essential amino acid solution (NEAA), 10\% (v/v) foetal bovine serum (FBS), at $37^{\circ} \mathrm{C}$ in an atmosphere of $5 \% \mathrm{CO}_{2}(\mathrm{ESCO}, \mathrm{UK})$ in the tissue culture flasks $\left(75 \mathrm{~cm}^{2}\right.$; Thermo, USA). Once cells were $90 \%$ confluent, $0.1 \%$ trypsin-EDTA solution was employed.

\subsubsection{Cell viability assay}

For cell viability studies, $1 \times 10^{3}$ cells $/ \mathrm{cm}^{2}$ were seeded on 96 well plates $(\mathrm{M} / \mathrm{s}$ Thermo Fischer Scientific, Roskilde, Denmark), and the cytotoxicity was evaluated by PrestoBlue ${ }^{\mathrm{TM}}$ cell viability reagent (Invitrogen, MD, USA). The medium was removed before the start of each experiment, and $90 \mu \mathrm{L}$ of $1000 \mu \mathrm{mol}$ concentration of Mgf, physical mixture, PLCs and PLCs-NLCs diluted with media were added to their respective wells. A volume of $10 \mu \mathrm{L}$ of PrestoBlue was added to each well after 24, 48 and $72 \mathrm{~h}$ of treatment, and the fluorescence was measured, after $1 \mathrm{~h}$ of incubation using a microtiter plate reader at excitation/emission 535/612 nm (Tecan, Genios Pro, Austria).

\subsubsection{Bidirectional permeability assay}

The cellular permeability of Mgf, physical mixture, PLCs and PLCs-NLCs was studied in the apical to basolateral $(\mathrm{A} \rightarrow \mathrm{B})$ and basolateral to apical $(\mathrm{B} \rightarrow \mathrm{A})$ directions in Caco- 
2 cells. To determine permeability on fully grown monolayer, cells $\left(2 \times 10^{4}\right.$ cells $\left./ \mathrm{cm}^{2}\right)$ were seeded on polyester sterile membrane, polystyrene plates and grown for 19-21 days (12 $\mathrm{mm}$ diameter inserts, $0.4 \mu \mathrm{m}$ pore size) (Corning Incorporated, $\left.\operatorname{Costar}^{\circledR}, \mathrm{NY}, \mathrm{USA}\right)$. The media was changed every alternate day such that there is no depletion of nutrients to the cells. Besides, transepithelial electrical resistance (TEER; Millicell@-ERS-2 Voltohm meter, M/s Millipore Corporation, Billerica, MA, USA) value was measured in order to monitor the uniform growth of the Caco-2 monolayer. TEER value is also an indicative of the extent of opening of cellular tight junctions (Chaurasiya et al., 2012; Sermkaew et al., 2013; Neves et al., 2015). The experiment was started on $21^{\text {st }}$ day, when the monolayers reached a constant TEER value, i.e., at about $1700 \mathrm{ohm}$ and equilibrated with pre-warmed HBSS. Further, on apical side $0.5 \mathrm{~mL}$ pre-warmed HBSS containing Mgf, physical mixture, PLCs and PLCs-NLCs, while $1.5 \mathrm{~mL}$ of blank HBSS was added to the basolateral side. On the similar heels, the same formulations were also added on B side and blank HBSS was added to the A side of the cells to better evaluate the permeability assay. Post incubation, $0.2 \mathrm{~mL}$ of medium at the B side was withdrawn at a periodic time intervals of $0.5 \mathrm{~h}, 1 \mathrm{~h}, 2 \mathrm{~h}$ and $3 \mathrm{~h}$, and replaced with fresh medium to investigate $\mathrm{A} \rightarrow \mathrm{B}$ transport. Similarly, from the apical side, $0.2 \mathrm{~mL}$ of medium was withdrawn and replaced with fresh medium for investigating $B \rightarrow A$ transport. Drug concentration on both the sides was determined using HPTLC analytical method (Khurana et al., 2016). From the linear slope of the plot between drug permeated and time, apparent permeability coefficient (Papp; cm/s) was determined:

$$
P a p p=\frac{\Delta Q / \Delta t}{\operatorname{Co} \times A}
$$


where, $\Delta Q / \Delta t$ is the steady state flux; $C_{0}$ is the initial drug concentration on apical or basolateral side; and $A$ is the surface area of the membrane $\left(\mathrm{cm}^{2}\right)$.

\subsubsection{Qualitative and quantitative cellular uptake}

Qualitative cellular uptake investigations were conducted by fluorescence microscopy on Caco-2 cells employing rhodamine-123 (Rh-123) as the tracker dye, loaded onto blank NLCs (Chaurasiya et al., 2012). Cells $\left(1 \times 10^{5}\right.$ per well $)$ were plated on glass coverslips in EMEM media and allowed to adhere overnight. Once adhered, the cells were treated with $0.078 \mu \mathrm{M} \mathrm{Rh}-123$ loaded NLCs for $1 \mathrm{~h}$ and $3 \mathrm{~h}$ at $37^{\circ} \mathrm{C}$. Subsequently, the cells were washed thrice with pre-warmed PBS and imaged live under PBS on a modified Zeiss Cell Observer imaging system using a Zeiss EC Plan-Neofluar 40x/1.3 oil objective. On the other hand, simultaneously another set of cells grown of cover slips were treated in a similar manner. However, these sets of cells were fixed with paraformaldehyde and washed thrice with PBS prior to their mounting on Vectashield ${ }^{\circledR}$ mounting medium with DAPI and were observed on the same instrument. Rh-123 and DAPI were imaged using a GFP/DAPI filter set at excitation/emission wavelength of $450-490 \mathrm{~nm} / 500-550 \mathrm{~nm}$ and $335-383 \mathrm{~nm} / 420-$ 470nm, respectively. Analysis of the images was carried out using Zeiss ZEN desk imaging software. For quantitative measurement, cells $\left(1 \times 10^{5}\right)$ were seeded in each well of the 6-well plate and incubated for overnight. Rh-123 loaded NLCs $(100 \mu \mathrm{g} / \mathrm{mL})$ were added to each well and cells were incubated for different time intervals, as during qualitative measurement. Medium was removed after incubation for a period of $1 \mathrm{~h}$ and $3 \mathrm{~h}$, subsequently, the cells were washed, tyrpsinized, and re-suspended in cold PBS for immediate flow cytometry analysis. Rh-123 signals were detected in FL- 
1 channel of BD FACSAria flow cytometer. A total of 10,000 events were analysed and data were analysed on Flowing version 2.5.1 (Pertuu Terho, Turku Centre for Biotechnology, University of Turko, Finland).

\subsubsection{P-gp efflux assay}

The overexpression of P-gp efflux proteins in Caco- 2 cells has been well documented in several literature reports (Faassen et al., 2003; Konsoula and Jung, 2009). In Caco-2 cells, P-gp confers resistance by preventing the absorption of drugs and bioactives through the cells, thereby inhibiting it to reach systemic circulation (Shugarts and Benet, 2009). For evaluating the P-gp efflux, the multi-drug resistance dye efflux assay kit (Chemicon International, USA) was employed (International, 2016). The efflux activity was measured to determine the intracellular accumulation of two fluorescent dyes viz. Rh-123 and $\mathrm{DiOC}_{2}$, to access the inhibitory activity of Mgf, PLC, PLCs-NLCs on MDR1 and BCRP transporters, respectively. Caco-2 pellet containing $2.5 \times 10^{5}$ cells was incubated with $\mathrm{Rh}-123$ alone, Rh- 123 with vinblastine at $37{ }^{\circ} \mathrm{C}$ and $4{ }^{\circ} \mathrm{C}$, Rh-123 loaded-PLCs and PLCs-NLCs for $1 \mathrm{~h}$. All the formulations were suspended in RPMI-1640 medium (Sigma-Aldrich, UK). Likewise, to investigate the potential of Mgf and the developed formulations to block the activity of BCRP transporters, $\mathrm{DiOC}_{2}$ dye was employed. Similarly, Caco-2 cells $\left(2.5 \times 10^{5}\right)$ were incubated with $\mathrm{DiOC}_{2}$ alone, $\mathrm{DiOC}_{2}$ and vinblastine at $37^{\circ} \mathrm{C}$ and $4{ }^{\circ} \mathrm{C}, \mathrm{DiOC}_{2}$-loaded Mgf, PLCs and PLCNLCs for another $1 \mathrm{~h}$. The cells were washed with pre-warmed PBS and the fluorescence intensity was measured in the presence of $\mathrm{Rh}-123$ and $\mathrm{DiOC}_{2}$-loaded formulations, in a Tecan fluorescence microplate reader at excitation and emission wavelengths of $485 \mathrm{~nm}$ and $530 \mathrm{~nm}$, respectively.

\subsection{In situ single pass intestinal perfusion (SPIP) studies}


Unisex wistar rats weighing 250-300 g were fasted for $24 \mathrm{~h}$ (Animal approval no. 578/IAEC). Animals were randomly grouped namely, i.e., Group I with Mgf, Group II Mgf with verapamil (a P-gp efflux inhibitor), Group III with PLCs, and Group IV with PLCs-NLCs. The study was performed as per the procedure already reported by our group (Bandyopadhyay et al., 2012). Briefly, on the anaesthized animal, the inlet and outlet was created on the intestine after incising the abdomen and were further cannulised to perfuse Kreb's buffer. After a periodic time interval of $15 \mathrm{~min}$, aliquots of $1 \mathrm{~mL}$ were withdrawn. Permeability parameters viz. effective and wall permeability, and absorption parameters viz. fraction absorbed and absorption number were calculated (Daniel, 1991; Singh et al., 2016).

\subsection{In vivo pharmacokinetic studies}

In vivo pharmacokinetic studies were conducted (Animal approval no. 578/IAEC) with single dose parallel design study. Each group contained six animals, Group I were administered with free Mgf solution, Group II were administered with PLCs and Group III were PLCs-NLCs complex containing Mgf equivalent to $30 \mathrm{mg} / \mathrm{Kg}$ by oral gavage (Lopesa et al., 2013), respectively. About $100 \mu \mathrm{L}$ of blood was withdrawn at 0.5 , $1,2,3,6,12,18,24$ and $36 \mathrm{~h}$ from the retro-orbital plexus. Heparin coated vials containing blood were centrifuged at $10,000 \mathrm{rpm}(5,590 \times \mathrm{g})$ for $10 \mathrm{~min}$ to extract plasma which was subjected to HPTLC analysis to estimate Mgf. The validation data of the developed method has already been previously reported by our group (Khurana et al., 2016). To estimate the pharmacokinetic parameters, data analysis was carried out using compartmental and noncompartmental modelling options of WinNonlin software, version 5.0 (M/s Thermo Scientific, USA) (Singh et al., 2009). 


\section{Results and Discussion}

The PLCs was formed employing stoichiometric ratios of 1:1, 1:2, and 1:3 and the following parameters were estimated to screen the best ratio.

\subsection{Systematic optimization of the NLCs}

\subsubsection{Defining the QTPP}

For maximal therapeutic efficacy and patient safety, the objectives of the target product were defined by summarizing the quality characteristics. Supplementary Table 1 enlists the QTPP aimed for formulating the NLCs of Mgf. The basic objective underlying the selection of NLCs can be ascribed to their lipidic nanostructured nature, which helps in absorption of the drugs through gastrointestinal route. Although several literature reports (Patil et al., 2015; Singh et al., 2016; Valicherla et al., 2016) have documented the use of lipidic systems for BCS Class II and IV bioactives like Mgf, yet the current studies endeavoured at developing the PLCs-loaded with NLCs systematically for enhance the oral bioavailability.

\subsubsection{Identification of the CQAs}

The CQAs for NLCs were earmarked to meet the desired QTPP objectives which include particle size, zeta potential, entrapment efficiency and time required for $80 \%$ of drug release. Selection criterion of the CQAs was based upon the prior literature, knowledge and experience on the NLCs formulations and enlisted in Supplementary Table 2 with suitable justifications.

\subsection{Molecular docking and simulation:}

Docking studies unearth the formation of intermolecular hydrogen bonding between Mgf and phosphatidylcholine transfer protein. As shown in Figure 1, the docking 
patterns indicated two prominent hydrogen bonding, between free hydroxyl groups of Mgf and NH of TRP 30 and GLN 12, at a distance of $1.982 \AA$ and $2.142 \AA$, respectively. The complex formation and thermodynamic stable conformation between Mgf and protein is primarily due to the meek reduction in the activation energy. Final docking energy exhibited was $-7.9 \mathrm{kcal} / \mathrm{mol}$, indicative of the free $-\mathrm{OH}$ groups on Mgf responsible for the complex formation (Beg et al., 2016).

\subsection{Characterization of PLCs}

\subsubsection{Physical evaluation and drug Content}

Mgf (10 mg) and Phosholipon 90G were stoichiometrically mixed in 1:1; 1:2 and 1:3 ratio to prepare the complex. The physical appearance of the complex was found to be semi-solid in nature, while evaluation content in all the three ratios (i.e., 1:1; 1:2 and 1:3) of complexes was found to be of $96.57 \% \pm 1.02 \%(1: 1), 95.64 \% \pm 0.92 \%(1: 2)$ and $95.18 \% \pm 1.11 \%$.

\subsubsection{Solubility and oil water partition coefficient}

All the complexes, prepared in different molar ratios, showed 25-folds higher aqueous solubility and 10-folds higher oil-water partition coefficient vis-a-vis Mgf alone (Table 1). It could be well inferred from the studies that varying ratios of Mgf and PL during complex formation caused no significant improvement in the values of solubility and partition coefficient of the drug. This indicated that 1:1 molar ratio was suitable for forming the complex between the Mgf and PL, which was selected for further studies.

Table 1: Solubility and oil-water partition coefficient of Mgf, physical mixture and PLCs

\begin{tabular}{|l|l|l|}
\hline Samples & Solubility in water $(\mathrm{mg} / \mathrm{mL})$ & Oil-water partition coefficients \\
\hline Mgf & $1.36 \pm 0.25$ & $0.83 \pm 0.21$ \\
\hline
\end{tabular}




\begin{tabular}{|l|l|l|}
\hline $\begin{array}{l}\text { Physical } \\
\text { mixture }\end{array}$ & $3.79 \pm 1.98$ & $1.23 \pm 0.54$ \\
\hline PLCs $(1: 1)$ & $34.25 \pm 1.98$ & $8.52 \pm 0.98$ \\
\hline PLCs $(1: 2)$ & $33.22 \pm 2.75$ & $8.91 \pm 1.26$ \\
\hline PLCs $(1: 3)$ & $34.46 \pm 1.10$ & $7.90 \pm 1.03$ \\
\hline
\end{tabular}

Mean \pm SD $(n=3)$

\subsubsection{PXRD studies}

The PXRD depicted in Figure 2 (A) for Mgf showed sharp peaks, indicating its highly crystalline nature, while a halo pattern was observed for PL indicating its amorphous nature (Figure $2 \mathrm{~B}$ ). Physical mixture of Mgf and PL (Figure $2 \mathrm{C}$ ) shows some of the prominent diffraction peaks of Mgf. On the contrary, diffraction patterns of PLCs (Figure 2 D) show a halo pattern indicating loss of crystallinity of Mgf in the PLCs.

\subsubsection{DSC studies}

The DSC heating curve in Figure 3 (A) for Mgf indicated a sharp endothermic peak at $277.08{ }^{\circ} \mathrm{C}$, ostensibly owing to the melting point of crystalline Mgf. Figure 3 (B), portraying PL, did not exhibit any distinct melting event plausibly due to its noncrystalline nature, while an endothermic peak at $231.13{ }^{\circ} \mathrm{C}$ was observed due to its possible degradation pattern. However, the physical mixture of Mgf and PL (Figure 3 C) exhibited significant reduction in the melting endotherm of Mgf which could be due to the miscibility of Mgf and PL. However, PLCs of Mgf shows a prominent endothermic event at around $140^{\circ} \mathrm{C}$ which might be attributed to formation of a characteristic ordered structure for the complex. It also showed disappearance of DSC events for pure Mgf and phospholipid (Semalty et al., 2012). The results were found to be in close consonance with those of the results reported by Ma and associates (Ma et al., 2014). 


\subsubsection{FTIR Studies}

The FTIR studies of Mgf (Figure 4 A) revealed functional groups of peaks at 3368.00 $\mathrm{cm}^{-1}\left(\mathrm{O}-\mathrm{H}_{\text {str }}\right), 2932.88 \mathrm{~cm}^{-1}$ (aliphatic C- $\left.\mathrm{H}_{\text {str }}\right), 1636.75 \mathrm{~cm}^{-1}\left(\mathrm{C}=\mathrm{O}_{\text {str }}\right), 1497.10 \mathrm{~cm}^{-1}(\mathrm{CH}-$ $\mathrm{CH}_{\text {str }}$ ) and $1253.42 \mathrm{~cm}^{-1}\left(\mathrm{C}-\mathrm{O}_{\text {str }}\right)$. Peak at $1086.93 \mathrm{~cm}^{-1}$ showed the presence of $\mathrm{C}-\mathrm{C}$ stretching in the structure of Mgf. The FTIR spectrum of PL (Figure 4 B) showed peaks for functional group at $3390.30 \mathrm{~cm}^{-1}\left(\mathrm{O}-\mathrm{H}_{\text {str }}\right), 2923.39 \mathrm{~cm}^{-1}$ (aliphatic C- $\left.\mathrm{H}_{\text {str }}\right), 1733.16$ $\mathrm{cm}^{-1}\left(\mathrm{C}=\mathrm{O}_{\text {str, }}, \mathrm{COOH}\right)$ and $1642.48 \mathrm{~cm}^{-1}\left(\mathrm{C}=\mathrm{O}_{\text {str }}\right)$.

The physical mixture, however, showed characteristic functional peaks (Figure 3 C) at $3369.44 \mathrm{~cm}^{-1}\left(\mathrm{O}-\mathrm{H}_{\text {str }}\right), 2926.75 \mathrm{~cm}^{-1}\left(\mathrm{C}-\mathrm{H}_{\text {str, }}\right.$ aliphatic), $1737.04 \mathrm{~cm}^{-1}$ (C=Ostr, $\mathrm{COOH}$, phospholipid) and $1640.85 \mathrm{~cm}^{-1}\left(\mathrm{C}=\mathrm{O}_{\mathrm{str}}, \mathrm{Mgf}\right)$, indicating no interaction existing between Mgf and PL. On the other hand, the complex showed shifting and broadening of the functional peaks of Mgf (Figure $3 \mathrm{D}$ ) from 3390.30 to $3430.87 \mathrm{~cm}^{-1}$ for $\mathrm{O}-\mathrm{H}_{\text {str }}$ indicating presence of weak $\mathrm{H}$-bonding interaction. These results indicated that phenolic hydroxyl group of Mgf might have been responsible for interaction with the quaternary amine nitrogen in the PL to form PLCs, while minor shifting in the peaks and their intensity were observed in the functional peaks from 1638.55 to $1430.91 \mathrm{~cm}^{-}$ ${ }^{1}$ (Zhao et al., 2013). The results are in consonance with the values reported in literature (Semalty et al., 2012).

\subsubsection{Scanning electron microscopy (SEM)}

Figure 5 illustrates the surface morphology of Mgf and its complex. The Figure 5 (A) shows longitudinal column shaped crystals of Mgf, while Figure 5 (B) shows amorphous nature of PL. No change in surface morphology was observed in the physical mixture of Mgf with PL, as depicted in Figure 5 (C). In case of complex 
(Figure $5 \mathrm{D}$ ), however, the crystallinity of Mgf disappeared ascribable to its complexation with PL.

As a naturally occurring flavonoid exhibiting poor lipophilicity (log $\mathrm{P}$ of -0.36 ) (FooDB., 2016) and hydrophilicity (sparingly solubility in water; $0.16 \mathrm{mg} / \mathrm{mL}$ ) (Acosta et al., 2016) as well as in lipidic solvents, phospholipids can be considered as potential carriers to ameliorate these hiccups of Mgf, a BCS Class IV bioactive. Therefore, phospholipid complex of Mgf i.e., PLCs were prepared first, then incorporated in the nanostructured lipidic carriers (NLCs) for improved scalability, deliverability through oral route and handling of drug delivery systems.

\subsection{Risk assessment studies}

The causes and sub-causes affecting the CQAs were indentified through Fish-bone diagram constructed in Supplementary Figure 1. Subsequently, the "prominent few" input variables were identified from the "plausible so many". These included drug particle size, type of phospholipid, type of surfactant, amount of solid lipid and liquid lipid, amount of emulgent as MAs and as the reflux temperature and time, ultrasonication time and cycles, type of stirring, stirring speed and stirring time, homogeniser speed and homogenisation time as process parameters (PPs). The selected MAs and PPs were subjected to risk assessment studies using REM by assigning them low, medium and high risk levels. These levels were earmarked keeping in consideration the patient perspectives following the brainstorming sessions among the team members. Supplementary Table 3 illustrates the REM with ratio of solid and liquid lipids, and amount of emulgent observed to be the high risk parameters influencing the formulation CQAs, i.e., particle size, zeta potential, 
encapsulation efficiency and in vitro drug release. Further, ultrasonication time and ultrasonication cycles, stirring speed and stirring time and homogeniser speed and homogenization time as the PPs were observed to exhibit medium risk levels. The aforesaid MAs and PPs were therefore, considered as critical CMAs and CPPs, and were further subjected to systematic formulation optimization studies. However, API particle size, and types of phospholipid and surfactant were found to exhibit low risks. Thus, phospholipid and surfactant type were fixed with i.e., Phospholipon 90G and Tween 80 on the basis of solubility results.

\subsection{Selection of the lipids}

Equilibrium solubility studies as Mgf were performed on various solid and liquid lipids. Solubility of drug in solid lipids was found to follow the order of Compritol $888>$ stearic acid $>$ isopropyl myristate $>$ cetyl palmitate $>$ glyceryl monostearate $>$ soy lecithin. Mgf showed maximal solubility in Compritol 888 while minimal solubility in soy lecithin. Soy lecithin was used in the formulation as an edge activator which enables the vesicle to deform without losing their structural integrity (Yusuf et al., 2014). Despite low solubility of the drug in it, many scientific reports on NLCs have documented the usage of soy lecithin for reducing the particle size and augmenting absorption characteristics of drug(s) (Andalib et al., 2012; Pezeshki et al., 2014). Solubility of drug in the liquid lipids and surfactants was found to follow the order, Labrafil M 2125 > Capmul MCM > Lauroglycol FCC > Capryol 90 and Tween 80> Tween 40> Cremophor RH 40> Cremophor EL. Hence, Labrafil M 2125 and Tween 80 were chosen as the liquid lipid and surfactant, respectively. Table 2 enlists the design matrix indicating thirteen experimental runs obtained for the NLCs, along with the 
factor levels in coded units and actual form. Prepared complex of Mgf was incorporated into the nanolipidic carriers through bottom-up approach, where the lipophilic complex was solubilized in the lipidic vehicle, used for the preparation of nanocarriers (Li et al., 2013; Beg et al., 2016).

Table 2: Optimization design matrix enlisting the levels employed for CMAs of NLCs in FCCD

\begin{tabular}{|c|c|c|c|c|}
\hline \multicolumn{2}{|r|}{ Factors } & \multirow[t]{2}{*}{ Type } & \multicolumn{2}{|c|}{ Levels } \\
\hline & & & Low (-1) & High (+1) \\
\hline & Solid lipid (X1) & Numerica & $700 \mathrm{mg}$ & $900 \mathrm{mg}$ \\
\hline & Tween $80(\mathrm{X} 2)$ & Numerica & $250 \mathrm{mg}$ & $450 \mathrm{mg}$ \\
\hline \multicolumn{5}{|c|}{ Optimization design as per thirteen factors, three level FCCD } \\
\hline Trials & Solid lipid (X1) & & \multicolumn{2}{|c|}{ Tween $80(\mathrm{X} 2)$} \\
\hline F1* & 0 & & \multicolumn{2}{|c|}{0} \\
\hline $\mathrm{F} 2 *$ & 0 & & \multicolumn{2}{|c|}{0} \\
\hline F3 & 0 & & \multicolumn{2}{|c|}{1} \\
\hline $\mathrm{F} 4^{*}$ & 0 & & \multicolumn{2}{|c|}{0} \\
\hline F5 & -1 & & \multicolumn{2}{|c|}{1} \\
\hline F6 & 0 & & \multicolumn{2}{|c|}{-1} \\
\hline F7* & 0 & & \multicolumn{2}{|c|}{0} \\
\hline F8 & 1 & & \multicolumn{2}{|c|}{1} \\
\hline F9 & -1 & & \multicolumn{2}{|c|}{-1} \\
\hline F10 & 1 & & \multicolumn{2}{|c|}{0} \\
\hline F11* & 0 & & \multicolumn{2}{|c|}{0} \\
\hline F12 & 1 & & \multicolumn{2}{|c|}{-1} \\
\hline F13 & -1 & & \multicolumn{2}{|c|}{0} \\
\hline
\end{tabular}




\subsection{Characterization of the prepared NLCs}

\subsubsection{Particle size and TEM analysis}

The NLCs showed particle size ranging between 151 and $415 \mathrm{~nm}$, which indicate their nanostructured nature, by and large. The results revealed that particle size was found to be depending on the combined effect of the solid lipid and concentration of the surfactant in the prepared formulations. The smaller particle size was observed for the formulations containing lower concentration of lipids and higher concentration of emulgents. Figure 6 (A) potrays the particle size and Figure 6 (B) depicts the electron microscopy analysis of optimized PLCs-NLCs.

\subsubsection{Zeta potential}

The zeta potential values for NLCs were found to be ranging between -10.41 and $-42.1 \mathrm{mV}$, indicating negatively charged nature of the prepared formulations. This can be attributed to the PEG-esters and a glycerides fraction of the lipid and nonionic nature of the surfactant employed for the preparation of NLCs (Pezeshki et al., 2014). The observed high values of zeta potential vouched potentially physical stability of the prepared NLCs.

\subsubsection{Encapsulation efficiency}

Encapsulation efficiency was found to be in the range of $68 \%$ and $87 \%$. High entrapment was observed with increasing lipid and intermediate levels of surfactant, attributable to the maximal drug solubilization capacity at this particular combination. The results revealed that use of intermediate to high concentration of lipids, and intermediate concentration of surfactant produced maximal entrapment efficiency values.

\subsubsection{In vitro drug release}


Figure 7 shows in vitro drug release profile of PLCs-loaded NLCs prepared as per design matrix and maximal drug release (i.e., $>80 \%$ ) was found to be within $20 \mathrm{~h}$. It was further observed that faster drug release was from the formulations containing lower concentration of lipid and higher amount of surfactant. However, the formulations containing intermediate to lower levels of lipids showed sustained drug release profile, plausibly owing to the slower diffusion rate of the drug from the tortuosity of the lipid matrix. Interestingly, the results also construed that the effect of increase in the levels of liquid lipid was responsible for evaluating drug release rate, ostensibly owing to loosening of the packing of drug within the lipid matrix (Dhawan et al., 2010). Mgf's PLCs-loaded NLCs exhibited sustained drug release profile, considered to be essential for enhancing the therapeutic response for prolonged period of time (Fang et al., 2012; Tran et al., 2014).

\subsubsection{DSC and FTIR analysis of PLCs-NLCs}

PLCs-NLCs showed a sharp new endothermic peak at $116.85^{\circ} \mathrm{C}$ (Figure $\left.3 \mathrm{E}\right)$ suggesting the disappearance of DSC events of Mgf, PL and PLCs. FTIR spectra obtained for PLCs-NLCs revealed peaks at $3433.51 \mathrm{~cm}^{-1}$ (O-H $\left.\mathrm{H}_{\text {str }}\right), 2923.69 \mathrm{~cm}^{-1}$ (C-H $\mathrm{H}_{\text {str, }}$ aliphatic) and changing of the intensity of all peaks from 1737.67 to $1105.40 \mathrm{~cm}^{-1}$ suggesting that PLCs have been incorporated in NLCs.

\subsection{Mathematical modelling and optimization}

MLRA method was employed to fit in the experimental data obtained as per the selected design into the second-order quadratic polynomial model. Table 3 enlists the coefficients obtained for each of the CQAs as per the model Eq. 1, which revealed the 
presence of interactions among the studied factors on the CQAs. Further, the model developed using parameters like higher values of correlation coefficient $(R)$, ranging from 0.9874 and 0.9988 and insignificant lack of fit revealed aptness of the selected model.

$Y=\beta_{0}+\beta_{1} X_{1}+\beta_{2} X_{2}+\beta_{3} X_{3}+\beta_{4} X_{1} X_{2}+\beta_{5} X_{2} X_{3}+\beta_{6} X_{1} X_{3}+\beta_{7} X_{1}^{2}+\beta_{8} X_{2}^{2}$

where, $Y=$ response variables, $\beta_{0}=$ intercept, $\beta_{1}$ to $\beta_{3}=$ coefficients of linear model terms; $\beta_{4}$ to $\beta_{6}=$ coefficients of linear interaction terms, $\beta_{7}$ to $\beta_{8}=$ coefficients of quadratic terms.

Table 3: Coefficients of polynomial model equations with various statistical parameters for the response variables of NLCs of mangiferin

\begin{tabular}{|c|c|c|c|c|}
\hline \multirow{2}{*}{$\begin{array}{l}\text { Coefficient } \\
\text { code }\end{array}$} & \multicolumn{4}{|c|}{ Polynomial coefficients for responses } \\
\hline & $\begin{array}{c}\text { Particle } \\
\text { size }\end{array}$ & $\begin{array}{c}\text { Zeta } \\
\text { potential }\end{array}$ & $\begin{array}{l}\text { Entrapment } \\
\text { efficiency }\end{array}$ & $\begin{array}{l}\text { Drug } \\
\text { release }\end{array}$ \\
\hline$\beta_{0}$ & 216.20 & -25.53 & 79.00 & 83.60 \\
\hline$\beta_{1}$ & -13.50 & 8.10 & 1.00 & 0.50 \\
\hline$\beta_{2}$ & -45.00 & 6.19 & -6.50 & -1.00 \\
\hline$\beta_{3}$ & 62.50 & 7.15 & 0.75 & -4.75 \\
\hline$\beta_{4}$ & 40.30 & -6.87 & 7.00 & 4.90 \\
\hline$\beta_{5}$ & 153.80 & 1.12 & -4.50 & 2.40 \\
\hline$\beta_{6}$ & 93.50 & -6.09 & 5.75 & -1.25 \\
\hline$\beta_{7}$ & 74.50 & -10.55 & -1.75 & -0.25 \\
\hline$\beta_{8}$ & 184.30 & 7.08 & 0.25 & -2.15 \\
\hline$R$ & 0.9996 & 0.9345 & 0.9240 & 0.9238 \\
\hline P-value & $<0.0001$ & $<0.001$ & $<0.001$ & $<0.001$ \\
\hline
\end{tabular}




\subsubsection{Response surface analysis}

The 3D-response surface plots as depicted in Figure 8, revealed the correlation among selected factors for better product and process understanding.

The said plots for particle size (Figure 8 A) revealed curvilinear relationship with an initial increasing trend from low to intermediate levels, followed by a declining phase at higher levels. On the other hand, the effect of Tween 80 was found to be quite linear on particle size. However, lower concentration of lipids and higher concentrations of surfactants showed minimum particle size.

In Figure 8 B, solid lipid shows a declining trend, while surfactant, i.e., Tween 80 shows positive influence on zeta potential. At lower levels of Tween 80 with increasing content of lipid, significant interaction was observed on the values of zeta potential. Maximal values for zeta potential were observed at higher concentration of lipids and surfactant.

The response surface plot depicting the influence of entrapment efficiency was found to be highly pronounced at all the levels of lipids (Figure $8 \mathrm{C}$ ). Moreover, the plot shows an initial declining trend followed by an increasing trend for entrapment efficiency from low to high levels of lipid, at high levels of surfactant. Maximum entrapment efficiency was observed both at either low or high solid lipid levels, coupled with preferably higher levels of surfactant.

The effect of ratio of solid to liquid lipid was found to possess positive influence on the values of $\mathrm{Q}_{16 \mathrm{~h}}$ (Figure $8 \mathrm{D}$ ), while the influence of Tween 80 shows a diminishing 
trend. Minimum percent drug release exhibiting controlled release profile was observed at higher lipid concentration and intermediate Tween 80 concentration.

\subsubsection{Search for the optimum formulation and validation studies}

To attain the desired intents of minimum particle size $(<90 \mathrm{~nm})$, higher zeta potential $(>22 \mathrm{mV})$, higher entrapment efficiency (>80\%) and amount of drug released at $20 \mathrm{~h}$ (80 to $90 \%$ ), various CQAs were trade off. Demarcation of the optimized formulation was done by making the desirability function close to unity. The concentration of liquid lipid, Labrafil M2125 was kept as constant, i.e., $230 \mathrm{mg}$. Figure 9 portrays the optimum location of NLCs formulation within design space, construing the formulation composition with Compritol 888 (770 mg) and Tween 80 (365 mg), exhibiting the particle size of $215 \mathrm{~nm}$, zeta potential of $-26.3 \mathrm{mV}$, entrapment efficiency of $78 \%$ and $\mathrm{Q}_{16 \mathrm{~h}}$ of $83.6 \%$, respectively.

\subsection{Caco-2 cell lines assays}

\subsubsection{Cell viability assay}

As Caco- 2 cells are very well to known possess similarity with the gastrointestinal epithelial cells, these are commonly used as the model cells for evaluating cytotoxicity, absorption and permeability of oral formulations (Kowapradit et al., 2010; Ma et al., 2014). These cells undergo spontaneous enterocytic differentiation and become polarized, thereby expressing apical and basolateral surfaces exhibiting tight junctions, therefore used as bidirectional permeability model (Sambuy et al., 2005; Awortwe et al., 2014). Hence, in the current research work, this cell lines was employed as an in vitro model to evaluate drug absorption across intestine. Figure 10 (A) depicts the concentration-dependent percent cell viability at $24 \mathrm{~h}$ and Figure $\mathbf{1 0}$ (B) shows the 
time-dependent percent cell viability at $24 \mathrm{~h}, 36 \mathrm{~h}$ and $48 \mathrm{~h}$ at highest concentration, i.e., $1000 \mu \mathrm{mol}$ for Mgf, PL, physical mixture, PLCs and PLCs-NLCs. The percent cell viability data with Presto Blue on Caco-2 cells (Lea et al., 2014) was found to be $>95 \%$ $(p>0.05)$ for all the formulations, i.e., upto a maximum of $72 \mathrm{~h}$, thus ratifying their safety and biocompatibility. Ideally, for better absorption and permeability, the formulation should not be toxic to the Caco-2 cells. Verily, Muller and associates have corroborated the safety of lipids on various cell lines in concentration of upto $10 \%$ (Müller et al., 1996; Müller et al., 2005). Indeed, none of the formulations, including Mgf, itself were found to be nontoxic to Caco-2 cells, and is in consonance with the literature findings (Caliph et al., 2000). For improved understanding, the control cells at all the time points have been assumed as $100 \%$ and the cell viability for tested formulations has been calculated accordingly (Coker et al., 2012; Cheah et al., 2014).

\subsubsection{Bidirectional permeability assay}

Further, it was conferred vital to assess the permeability of the formed PLCs-NLCs across the intestinal epithelial barrier (Hubatsch et al., 2007). As Mgf is quite prone to P-gp efflux, the strategy aimed not only to study the $\mathrm{A} \rightarrow \mathrm{B}$ permeation but also to investigate the $\mathrm{B} \rightarrow \mathrm{A}$ transport. Mgf was analysed in both the A and B compartments to calculate the value of Papp (Figure 11). The TEER values were continuously recorded while performing experiment, showing miniscule reduction (i.e., $<10 \%$ ) in TEER value on the treated cells wrt the control cells which indicated that there was slight opening of the tight junctions of Caco-2 cells, signifying paracellular transport (Sha et al., 2005; Chen et al., 2015; Laksitorini et al., 2015).

The prepared PLCs-NLCs and PLCs showed 10.1 fold $(\mathrm{p}<0.001)$ and 9.4 fold $(\mathrm{p}$ 
$<0.001)$ enhancement, respectively in the permeation $\left(19.2 \times 10^{-6} \mathrm{~cm} / \mathrm{sec}\right.$ and $15.4 \times$ $\left.10^{-6} \mathrm{~cm} / \mathrm{sec}\right)$ parameters in contrast to the plain Mgf solution $\left(1.9 \times 10^{-6} \mathrm{~cm} / \mathrm{sec}\right)$ at $3^{\text {rd }}$ hour. This indicated that PLCs-NLCs demonstrated enhanced permeability of Mgf, solely attributable to the lipids and phospholipids employed to prepare the complex and NLCs (Gursoy et al., 2003; Gursoy and Benita, 2004; Kogan et al., 2008).

The transport and permeability studies in Caco-2 monolayer determine the ability of a compound and/or formulation to act as a substrate and/or inhibitor of the efflux transporters of P-gp (Sun and Pang, 2008). Further, increase in the Papp with time might be due to the capacity of the excipients viz. phospholipids, lipids and surfactants to block the P-gp efflux mechanism across the intestinal barrier, resulting in more permeation over increasing time (Chaurasiya et al., 2012).

\subsubsection{Qualitative and quantitative cellular uptake}

Qualitative analysis made through the images were processed through Zen Pro 2012, displayed the fluorescent images of Rh-123-loaded NLCs uptake at $1 \mathrm{~h}$ and $3 \mathrm{~h}$ points, with the corresponding histograms generated through Flowing software version 2.5.1 (University of Turko, Finland) depict the quantitative data (Figure 12 A). Another set of images generated after fixation of cells exhibit DAPI stained nucleus of Caco-2 cells and Rh-123 loaded NLCs uptake at $1 \mathrm{~h}$ and $3 \mathrm{~h}$ (Fig 12B). Qualitative and quantitative analysis both made through the FITC value generated for respective time-points supported the time dependent uptake of 123 loaded NLCs upto 3h. This is in agreement with an earlier report where glyceryl monostearate lipid nanaoparticles showed maximum cellular uptake at 3 h (Garanti et al., 2016). 


\subsubsection{P-gp efflux assay}

The P-gp efflux assay revealed that at $37{ }^{\circ} \mathrm{C}$, MDR1 and BCRP transporters were effluxing dyes, as the fluorescence intensity for both the dyes was observed to be quite low (Figure 13). On the other hand, incubation at $37{ }^{\circ} \mathrm{C}$ with vinblastine showed higher fluorescence indicating that vinblastine might block both the MRP2 and BCRP transporters (International, 2016). Meanwhile, incubating dyes-loaded PLCs $(\mathrm{p}<0.0001)$ and PLCs-NLCs $(\mathrm{p}<0.0001)$ with Caco-2 showed significantly higher fluorescence intensity than Mgf alone. Verily, significant difference around 2..1 folds was found between the fluorescence intensity of PLCs and PLCs-NLCs $(p<0.001)$ which could be attributable to P-gp inhibition property of phospholipids and lipidic mixtures. These excipients primarily act as $\mathrm{P}$-gp inhibitors by rendering P-gp substrate site competition (Roger et al., 2010; Hoosain et al., 2015). In this context, Tween 80, being a surfactant also seemed to play significant role in inhibiting P-gp, leading to membrane fluidization and consequently, enhanced permeability (Rege et al., 2002).

\subsection{In situ intestinal perfusion studies}

The in situ SPIP study is a well-known model to investigate the absorption and permeation behaviour of a drug when administered as complex (Singh et al., 2009). As is evident from Figure 14, the PLCs showed significant improvement $(\mathrm{P}<0.001)$ in he absorption number $(\mathrm{An})$ by 12 -fold $(\mathrm{P}<0.001)$, fraction of drug absorbed $(\mathrm{F})$ by 11 fold ( $\mathrm{P}<0.001)$, effective permeability ( $\mathrm{P}_{\text {eff }}$ by 8 -fold $(\mathrm{P}<0.001)$ and wall permeability ( $\left.\mathrm{P}_{\text {wall }}\right)$ by 12-fold $(\mathrm{P}<0.001)$ vis-à-vis free Mgf or co-administered with verapamil. Verapamil could bind with the P-gp efflux pumps present on the intestinal 
enterocytes, thereby allowing the Mgf to reach systemic circulation (Ishri et al., 2006). This study indisputably demonstrated the inherent P-gp efflux characteristics of Mgf, while the formed PLCs could surmount the P-gp efflux (Madan et al., 2005). This can be attributed to the notable increase in the absorption potential of Mgf, due to enhanced permeability and absorption parameters by circumventing first-pass effect (Singh et al., 2011). Besides, the results unrevealed supremacy in permeability parameters by PLCs possibly due to phospholipids (Song et al., 2006; Zakeri-Milani et al., 2007).

\subsection{In vivo Pharmacokinetic Studies}

Statistically significant change in plasma concentration $(\mathrm{p}<0.001)$ was observed for PLCs-NLCs, PLCs than Mgf after peroral administration. The dose administered in each case, i.e., PLCs-NLCs, PLCs and Mgf, was equivalent to $30 \mathrm{mg} / \mathrm{kg}$ (Ma et al., 2014). The mean plasma and time profiles for each group $(n=6)$ is graphically depicted in Figure 15, depicting decline in the later part, thus, ratifying the suitability of 2-CBM kinetics (Bhattacharyya et al., 2013). The values of various pharmacokinetic parameters of PLCs and Mgf, and the results of post one-way Anova test are shown in Table 4.

Nearly 4.55- and 1.98-fold increase in $\mathrm{C}_{\max }$ and AUC was recorded by PLCs-NLCs, while the corresponding PLCs demonstrated 3.61- and 1.78-fold augmentation vs Mgf, respectively. Moreover, the PLCs-NLCs and NLCs showed nearly 3-fold reduction in $t_{\max }$ values vs Mgf, therefore, suggested enhanced absorption with faster onset of action. Drastic increase for Ka, i.e., 5.14-fold, demonstrated increased oral absorption 
of PLCs-NLCs. Thus, significant different pharmacokinetic parameters confirm the better oral absorption of PLCs-NLCs over PLCs and Mgf.

Together lipids, surfactants and absorption enhancers facilitate the increased bioavailability because of nanostructured NLCs, micellar solubilisation in intestinal milieu, followed by increased intestinal transport through transcellular and paracellular pathways (Porter et al., 2007).

Table 4: Pharmacokinetic parameters obtained from plasma level studies after oral administration of PLCs-NLCs, PLCs and Mgf

\begin{tabular}{|c|c|c|c|c|c|c|c|}
\hline \multirow{2}{*}{$\begin{array}{c}\text { Treatment } \\
\text { Formulations }\end{array}$} & \multicolumn{7}{|c|}{ Pharmacokinetic parameters } \\
\hline & $\begin{array}{l}\mathrm{C}_{\max } \\
\left(\mathrm{ngh}^{-1}\right)\end{array}$ & $\begin{array}{l}\text { AUC last } \\
h^{*} n g / m l\end{array}$ & $\begin{array}{l}\mathrm{C}_{\max } / \mathrm{AUC} \\
\left(\mathrm{h}^{-1}\right)\end{array}$ & $\begin{array}{l}\mathrm{Ka} \\
\left(\mathrm{h}^{-1}\right)\end{array}$ & $\begin{array}{l}T_{\max } \\
\text { (h) }\end{array}$ & $\begin{array}{l}\text { MRT } \\
\text { (h) }\end{array}$ & $\begin{array}{l}\mathrm{Cl} \\
(\mathrm{mL} / \mathrm{h})\end{array}$ \\
\hline Mgf & $\begin{array}{l}275.14 \quad \pm \\
42.76\end{array}$ & $\begin{array}{l}2851.39 \pm \\
238.91\end{array}$ & 0.096 & $\begin{array}{l}1.08 \pm \\
2.1\end{array}$ & $\begin{array}{l}3.02 \pm \\
0.15\end{array}$ & $\begin{array}{l}9.72 \pm \\
1.27\end{array}$ & $\begin{array}{l}2331.64 \\
\pm \\
591.71\end{array}$ \\
\hline PLCs & $\begin{array}{l}1046.56 \pm \\
166.35\end{array}$ & $\begin{array}{l}5349.75 \quad \pm \\
311.56\end{array}$ & 0.196 & $\begin{array}{l}0.35 \pm \\
0.12\end{array}$ & $\begin{array}{l}1.05 \pm \\
0.21\end{array}$ & $\begin{array}{l}12.72 \pm \\
1.87\end{array}$ & $\begin{array}{l}1445.51 \\
\pm \\
265.12 \\
\end{array}$ \\
\hline PLCs-NLCs & $\begin{array}{l}1319.12 \pm \\
178.53\end{array}$ & $\begin{array}{l}5948.72 \pm \\
378.26\end{array}$ & 0.222 & $\begin{array}{ll}0.21 \quad \pm \\
0.13\end{array}$ & $\begin{array}{l}1.03 \pm \\
0.36\end{array}$ & $\begin{array}{l}13.89 \pm \\
1.85\end{array}$ & $\begin{array}{l}1045.51 \\
\pm \\
291.91\end{array}$ \\
\hline
\end{tabular}

All the data represented as mean \pm SD $(n=3)$

Although PLCs-NLCs did not show much significant improvement over the PLCs in the pharmacokinetic parameters (only 1.2 folds enhancement), yet the prepared PLCsNLCs exhibited quite superior results during inhibition of P-gp efflux activity (2.1 folds), when conducted on Caco-2 cells. This can be ostensibly attributed to the presence of phospholipids and lipids present in the PLCs-NLCs, which act as P-gp substrates. Thus, the prepared PLCs-NLCs formulation primarily showed superiority on P-gp efflux inhibition potential, although not much significant effect on the pharmacokinetic profile. 


\section{Conclusions:}

A dual formulation strategy was adopted in order to enhance the biopharmaceutical attributes of a very potent antioxidant, Mgf. A minimum stiochiometric ratio of Mgf:PL (1:1) was observed to be good enough to form the complex on the basis of drug content, solubility and oil-water partition coefficient. Higher solubility and permeability values may lead to increased intestinal uptake and permeability, which is indeed a big limitation for oral absorption. Hence, the PLCs showed different morphological properties from Mgf and the physical mixture. Being semisolid in nature, attempts were made to incorporate Mgf in nanostructured carriers. Hence, a novel strategy with dual formulation, i.e., PLCs encapsulated in nanostructured systems was undertaken to improve the physicochemical and biopharmaceutical attributes of Mgf through in vitro, in situ and in vivo studies. The current research studies ratified that this drug-phospholipid complex loaded nanostructured dual system is a novel strategy to formulate BCS Class II and IV drugs.

\section{Declaration of interest}

Authors declare no conflict(s) interest.

\section{Acknowledgements}

The financial grants received from the University Grant Commission (UGC), New Delhi, India, to Ms Rajneet Kaur Khurana under the RFMS scheme-F. No. 594/2007(BSR) is deeply acknowledged. Also, the services provided by SEM department of Central Instrumental Laboratory, Panjab University is highly appreciable. Use of Biomedical research facilities at University of Central Lancashire 
is acknowledged. We are also thankful for the generous supply of hard gelatin capsules shells ex-gratis by M/s ACG capsules, Pvt. Ltd. India.

\section{References:}

Acosta, J., Sevilla, I., Salomón, S., Nuevas, L., Romero, A., Amaro, D., 2016. Determination of mangiferin solubility in solvents used in the biopharmaceutical industry. J. Pharm. Pharmacogn. Res. 4, 49-53.

Andalib, S., Varshosaz, J., Hassanzadeh, F., Sadeghi, H., 2012. Optimization of LDL targeted nanostructured lipid carriers of 5-FU by a full factorial design. Adv. Biomed. Res. 1, 45.

Awortwe, C., Fasinu, P., Rosenkranz, B., 2014. Application of Caco-2 Cell Line in Herb-Drug Interaction Studies: Current Approaches and Challenges. J Pharm Pharm Sci 17, 1-19.

Bandyopadhyay, S., Katare, O.P., Singh, B., 2012. Optimized self nano-emulsifying systems of ezetimibe with enhanced bioavailability potential using long chain and medium chain triglycerides. Colloids. Surf. B. Biointerfaces. 100, 50-61.

Basheer, L., Kerem, Z., 2015. Interactions between CYP3A4 and Dietary Polyphenols. Oxid. Med. Cell. Longev. 2015, 854015.

Beg, S., Raza, K., Kumar, R., Chadha, R., Katare, O.P., Singh, B., 2016. Improved intestinal lymphatic drug targeting via phospholipid complex-loaded nanolipospheres of rosuvastatin calcium. RSC. Adv. 6, 8173-8187.

Beg, S., Sharma, G., Thanki, K., Jain, S., Katare, O.P., Singh, B., 2015. Positively charged selfnanoemulsifying oily formulations of olmesartan medoxomil: Systematic development, in vitro, ex vivo and in vivo evaluation. Int. J. Pharm. 493, 466-482.

Bhattacharyya, S., Ahmmed, S.M., Saha, B.P., Mukherjee, P.K., 2013. Soya phospholipid complex of mangiferin enhances its hepatoprotectivity by improving its bioavailability and pharmacokinetics. J Sci Food Agric 94, 1380-1388.

Bunjes, H., 2010. Lipid nanoparticles for the delivery of poorly water-soluble drugs. J Pharm Pharmacol. 62, 1637-1645.

Caliph, S.M., Charman, W.N., Porter, C.J., 2000. Effect of short-, medium-, and long-chain fatty acidbased vehicles on the absolute oral bioavailability and intestinal lymphatic transport of halofantrine and assessment of mass balance in lymph-cannulated and non-cannulated rats. J. Pharm. Sci. 89, 10731084.

Chaurasiya, A., Singh, A.K., Jain, G.K., Warsi, M.H., Sublet, E., Ahmad, F.J., Borchard, G., Khar, R.K., 2012. Dual approach utilizing self microemulsifying technique and novel $P$-gp inhibitor for effective delivery of taxanes. J Microencapsul 29, 583-595.

Cheah, K.Y., Howarth, G.S., Bastian, S.E., 2014. Grape seed extract dose-responsively decreases disease severity in a rat model of mucositis; concomitantly enhancing chemotherapeutic effectiveness in colon cancer cells. PLoS One. 9, e85184.

Chen, S., Einspanier, R., Schoen, J., 2015. Transepithelial electrical resistance (TEER): a functional parameter to monitor the quality of oviduct epithelial cells cultured on filter supports. Histochem Cell Biol 144, 509-515.

Coker, A., Arisan, E.D., Palavan-Unsal, N., 2012. Silencing of the polyamine catabolic key enzyme SSAT prevents CDK inhibitor-induced apoptosis in Caco-2 colon cancer cells. Mol Med Rep. 5, 1037-1042.

da Rocha Ferreira, F., Valentim, I.B., Luís Catarí Ramones, E., Salles Trevisan, M.T., Olea-Azar, C., PerezCruz, F., de Abreu, F.C., Fonseca Goulart, F.G., 2013. Antioxidant activity of the mangiferin inclusion complex with $\beta$-cyclodextrin. LWT - Food Sci and Tech 51, 129-134.

Daniel, W.W., 1991. Biostatistics : A foundation for analysis in the health sciences, 5th ed. ed. Wiley \& Sons, New York.

Dar, A., Faizi, S., Naqvi, S., Roome, T., Zikr-ur-Rehman, S., Ali, M., Firdous, S., Moin, S.T., 2005. Analgesic and antioxidant activity of mangiferin and its derivatives: the structure activity relationship. Biol. Pharm. Bull. 28, 596-600. 
Dhawan, S., Kapil, R., Singh, B., 2010. Formulation development and systematic optimization of solid lipid nanoparticles of quercetin for improved brain delivery. J. Pharm. Pharmacol. 63, 342-351.

Faassen, F., Vogel, G., Spanings, H., Vromans, H., 2003. Caco-2 permeability, P-glycoprotein transport ratios and brain penetration of heterocyclic drugs. Int J Pharm. 263, 113-122.

Fang, M., Jin, Y., Bao, W., Gao, H., Xu, M., Wang, D., Wang, X., Yao, P., Liu, L., 2012. In vitro characterization and in vivo evaluation of nanostructured lipid curcumin carriers for intragastric administration. Int J Nanomedicine 7, 5395-5404.

FooDB., 2016. Showing Compound Mangiferin (FDB012803). http://foodb.ca/ compounds/FDB012803.

Garanti, T., Stasik, A., Burrow, A.J., Alhnan, M.A., Wan, K.W., 2016. Anti-glioma activity and the mechanism of cellular uptake of asiatic acid-loaded solid lipid nanoparticles. Int. J. Pharm. 500, 305315.

Gursoy, N., Garrigue, J.S., Razafindratsita, A., Lambert, G., Benita, S., 2003. Excipient effects on in vitro cytotoxicity of a novel paclitaxel self-emulsifying drug delivery system. J. Pharm. Sci. 92, 2411-2418.

Gursoy, R.N., Benita, S., 2004. Self-emulsifying drug delivery systems (SEDDS) for improved oral delivery of lipophilic drugs. Biomed Pharmacother. 58, 173-182.

Hoosain, F.G., Choonara, Y.E., Tomar, L.K., Kumar, P., Tyagi, C., du Toit, L.C., Pillay, V., 2015. Bypassing P-glycoprotein drug ffflux mechanisms: Possible applications in pharmacoresistant schizophrenia therapy. BioMed Res Int Article ID 484963, 1-21.

Hubatsch, I., Ragnarsson, E.G., Artursson, P., 2007. Determination of drug permeability and prediction of drug absorption in Caco-2 monolayers. Nat. Protoc. 2, 2111-2119.

International, C., 2016. Multidrug Resistance Direct Dye Efflux Assay. Cat. No. ECM910.

Ishri, R.K., Menzies, S., Halliday, G.M., 2006. Verapamil induces upregulation of P-glycoprotein expression on human monocyte derived dendritic cells. Immunol. Invest. 35, 1-18.

Khan, S., Baboota, S., Ali, J., Khan, S., Narang, R.S., Narang, J.K., 2015. Nanostructured lipid carriers: An emerging platform for improving oral bioavailability of lipophilic drugs. Int. J. Pharm. Investig. 5, 182-191.

Khurana, R.K., Rao, S., Beg, S., Katare, O.P., Singh, B., 2016. Systematic Development and Validation of a Thin-Layer Densitometric Bioanalytical Method for Estimation of Mangiferin Employing Analytical Quality by Design (AQbD) Approach. J. Chromatogr. Sci. 54, 829-841.

Kogan, A., Kesselman, E., Danino, D., Aserin, A., Garti, N., 2008. Viability and permeability across Caco2 cells of CBZ solubilized in fully dilutable microemulsions. Colloids. Surf. B. Biointerfaces. 66, 1-12.

Konsoula, Z., Jung, M., 2009. Involvement of $\mathrm{p}$-glycoprotein and multidrug resistance associated protein 1 on the transepithelial transport of a mercaptoacetamide-based histone-deacetylase Inhibitor in Caco-2 Cells. Biol Pharm Bull. 32, 74-78.

Kowapradit, J., Opanasopit, P., Ngawhirunpat, T., Apirakaramwong, A., Rojanarata, T., Ruktanonchai, U., Sajomsang, W., 2010. In vitro permeability enhancement in intestinal epithelial cells (Caco-2) monolayer of water soluble quaternary ammonium chitosan derivatives. AAPS PharmSciTech. 11, 497508.

Laksitorini, M.D., Kiptoo, P.K., On, N.H., Thliveris, J.A., Miller, D.W., Siahaan, T.J., 2015. Modulation of Intercellular Junctions by Cyclic-ADT Peptides as a Method to Reversibly Increase Blood-Brain Barrier Permeability. J Pharm Sci. 104, 1065-1075.

Lea, M.A., Pourat, J., Patel, R., desBordes, C., 2014. Growth inhibition of colon cancer cells by compounds affecting AMPK activity. World. Gastrointest. Oncol. 6, 244-252.

Lee, S.J., Wang, S., Borschel, W., Heyman, S., Gyore, J., Nichols, C.G., 2013. Secondary anionic phospholipid binding site and gating mechanism in Kir2.1 inward rectifier channels. Nat. Commun. 4, 2786.

Leiro, J., Arranz, J.A., Yanez, M., Ubeira, F.M., Sanmartin, M.L., Orallo, F., 2004. Expression profiles of genes involved in the mouse nuclear factor-kappa $B$ signal transduction pathway are modulated by mangiferin. Int. Immunopharmacol. 4, 763-778. 
Li, M., Zheng, Y., Shan, F.Y., Zhou, J., Gong, T., Zhang, Z.R., 2013. Development of ionic-complex-based nanostructured lipid carriers to improve the pharmacokinetic profiles of breviscapine. Acta Pharmacol Sin. 34, 1108-1115.

Lopesa, S.C., da Silvaa, A.V.L., Arrudaa, B.R., Moraisa, T.C., Riosc, J.B., Trevisanc, M.T.S., Raoa, V.S., Santos, F.A., 2013. Peripheral antinociceptive action of mangiferin in mouse models of experimental pain: Role of endogenous opioids, KATP-channels and adenosine. Pharmacol. Biochem. Behavior. 110, 19-26.

Ma, H., Chen, H., Sun, L., Tong, L., Zhang, T., 2014. Improving permeability and oral absorption of mangiferin by phospholipid complexation. Fitoterapia. 93, 54-61.

Madan, J., Chawla, G., Arora, V., Malik, R., Bansal, A.K., 2005. Unbiased membrane permeability parameters for gabapentin using boundary layer approach. AAPS. J. 7, E224-230.

Minglin, L., Huili, M., Lixin, Y., Peng, L., 2016. Mangiferin inhibition of proliferation and induction of apoptosis in human prostate cancer cells is correlated with downregulation of B-cell lymphoma-2 and upregulation of microRNA-182. Oncol. 11, 817-822.

Mukherjee, S., Ray, S., Thakur, R.S., 2009. Solid Lipid Nanoparticles: A Modern Formulation Approach in Drug Delivery System. Indian J Pharm Sci. 71, 349-358.

Müller, R., Maaßen, S., Weyhers, H., Specht, F., Lucks, J., 1996. Cytotoxicity of magnetite-loaded polylactide, polylactide/glycolide particles and solid lipid nanoparticles. Int J Pharm. 138, 85-94.

Müller, R.H., Souto, E.B., Göppert, T., Gohla, S., 2005. Production of biofunctionalized solid lipid nanoparticles for site-specific drug delivery. Nanotechnologies for the life sciences biological and pharmaceutical nanomaterials., 291-307.

Naseri, N., Valizadeh, H., Zakeri-Milani, P., 2015. Solid Lipid Nanoparticles and Nanostructured Lipid Carriers: Structure. Adv. Bull. 5, 305-313.

Neuberg, P., Perino, A., Morin-Picardat, E., Anton, N., Darwich, Z., Weltin, D., Mely, Y., Klymchenko, A.S., Remy, J.S., Wagner, A., 2015. Photopolymerized micelles of diacetylene amphiphile: physical characterization and cell delivery properties. Chem. Commun (Camb). 51, 11595-11598.

Neves, A.R., Queiroz, J.F., Costa Lima, S.A., Figueiredo, F., Fernandes, R., Reis, S., 2015. Cellular uptake and transcytosis of lipid-based nanoparticles across the intestinal barrier: Relevance for oral drug delivery. J. Colloid. Interface. Sci. 463, 258-265.

Ojewole, J.A., 2005. Antiinflammatory, analgesic and hypoglycemic effects of Mangifera indica Linn. (Anacardiaceae) stem-bark aqueous extract. Methods Find Exp Clin Pharmacol. 27, 547-554.

Patil, H., Feng, X., Ye, X., Majumdar, S., Repka, M.A., 2015. Continuous production of fenofibrate solid lipid nanoparticles by hot-melt extrusion technology: A systematic study based on a Quality by Design approach. AAPS J. 17, 194-205.

Pezeshki, A., Ghanbarzadeh, B., Mohammadi, M., Fathollahi, I., Hamishehkar, H., 2014. Encapsulation of Vitamin A Palmitate in Nanostructured Lipid Carrier (NLC)-Effect of Surfactant Concentration on the Formulation Properties. Adv. Bull. 4, 563-568.

Pichot, R., Watson, R.L., Norton, I.T., 2013. Phospholipids at the Interface: Current Trends and Challenges. Int. Mol. Sci. 14, 11767-11794.

Porter, C.J., Trevaskis, N.L., Charman, W.N., 2007. Lipids and lipid-based formulations: optimizing the oral delivery of lipophilic drugs. Nat. Rev. Drug. Discov. 6, 231-248.

Qin, L., Yujiang, W., Gang, D., Zhiping, W., Xuejian, L., Wanna, X., Jianjun, H., 2014. Multi-element mangiferin solid dispersion as well as preparation method and application thereof Guangxi University of Traditional Chinese Medicine. CN 104473875 A2014.

Rawat, D.S., Thakur, B.K., Semalty, M., Semalty, A., Badoni, P., Rawat, M.S., 2013. Baicaleinphospholipid complex: a novel drug delivery technology for phytotherapeutics. Curr. Drug. Discov. Technol. 10, 224-232.

Rege, B.D., Kao, J.P., Polli, J.E., 2002. Effects of nonionic surfactants on membrane transporters in Caco-2 cell monolayers. Eur J Pharm Sci. 16, 237-246.

Renukuntla, J., Vadlapudi, A.D., Patel, A., Boddu, S.H.S., Mitra, A.K., 2013. Approaches for Enhancing Oral Bioavailability of Peptides and Proteins. Int. J. Pharm. 447, 75-93. 
Rodriguez, J., Di Pierro, D., Gioia, M., Monaco, S., Delgado, R., Coletta, M., Marini, S., 2006. Effects of a natural extract from Mangifera indica $L$, and its active compound, mangiferin, on energy state and lipid peroxidation of red blood cells. Biochim. Biophys. Acta. 1760, 1333-1342.

Roger, E., Lagarce, F., Garcion, E., Benoit, J.P., 2010. Reciprocal competition between lipid nanocapsules and P-gp for paclitaxel transport across Caco-2 cells. Eur J Pharm Sci. 40, 422-429.

Saha, S., Sadhukhan, P., Sil, P.C., 2016. Mangiferin: A xanthonoid with multipotent anti-inflammatory potential. Biofactors. 42, 459-474.

Sambuy, Y., De Angelis, I., Ranaldi, G., Scarino, M.L., Stammati, A., Zucco, F., 2005. The Caco-2 cell line as a model of the intestinal barrier: influence of cell and culture-related factors on Caco- 2 cell functional characteristics. Cell Biol Toxicol. 21, 1-26.

Sánchez-Moreno, P., Ortega-Vinuesa, J.L., Martín-Rodríguez, A., Boulaiz, H., Marchal-Corrales, J.A., Peula-García, J.M., 2012. Characterization of Different Functionalized Lipidic Nanocapsules as Potential Drug Carriers. Int. J. Mol. Sci. 13, 2405-2424.

Sarkar, A., Sreenivasan, Y., Ramesh, G.T., Manna, S.K., 2004. Beta-D-Glucoside suppresses tumor necrosis factor-induced activation of nuclear transcription factor kappaB but potentiates apoptosis. $J$. Biol. Chem. 279, 33768-33781.

Semalty, A., Semalty, M., Singh, D., Rawat, M.S.M., 2012. Phyto-phospholipid complex of catechin in value added herbal drug delivery. J Incl Phenom Macrocycl Chem. 73, 377.

Sermkaew, N., Wiwattanawongsa, K., Ketjinda, W., Wiwattanapatapee, R., 2013. Development, Characterization and Permeability Assessment Based on Caco-2 Monolayers of Self-Microemulsifying Floating Tablets of Tetrahydrocurcumin. AAPS. PharmSciTech. 14, 321-331.

Sha, X., Yan, G., Wu, Y., Li, J., Fang, X., 2005. Effect of self-microemulsifying drug delivery systems containing Labrasol on tight junctions in Caco-2 cells. Eur J Pharm Sci. 24, 477-486.

Shah, N.V., Seth, A.K., Balaraman, R., Aundhia, C.J., Maheshwari, R.A., Parmar, G.R., 2016. Nanostructured lipid carriers for oral bioavailability enhancement of raloxifene: Design and in vivo study. J. Adv. Res. 7, 423-434.

Shugarts, S., Benet, L.Z., 2009. The Role of Transporters in the Pharmacokinetics of Orally Administered Drugs. Pharm Res. 26, 2039-2054.

Singh, B., Bandopadhyay, S., Kapil, R., Singh, R., Katare, O., 2009. Self-emulsifying drug delivery systems (SEDDS): Formulation development, characterization, and applications. Crit. Rev. Ther. Drug Carrier Syst. 26, 427-521.

Singh, B., Kaur, A., Dhiman, S., Garg, B., Khurana, R.K., Beg, S., 2016. QbD-enabled development of novel stimuli-responsive gastroretentive systems of acyclovir for improved patient compliance and biopharmaceutical performance. AAPS. PharmSciTech. 17, 454-465.

Singh, B., Khurana, L., Bandyopadhyay, S., Kapil, R., Katare, O.P., 2011. Development of optimized selfnano-emulsifying drug delivery systems (SNEDDS) of carvedilol with enhanced bioavailability potential. Drug Deliv. 18, 599-612.

Singh, B., Kumar, R., Ahuja, N., 2005. Optimizing drug delivery systems using systematic "design of experiments." Part I: fundamental aspects. Crit. Rev. Ther. Drug Carrier Syst 22, 27-105.

Singh, D., Rawat, M.S., Semalty, A., Semalty, M., 2012. Rutin-phospholipid complex: an innovative technique in novel drug delivery system- NDDS. Curr. Drug Deliv. 9, 305-314.

Song, N.N., Li, Q.S., Liu, C.X., 2006. Intestinal permeability of metformin using single-pass intestinal perfusion in rats. World J. Gastroenterol. 12, 4064-4070.

Souza, J.R.R.d., Feitosa, J.P.A., Ricardo, N.M.P.S., Trevisan, M.T.S., Paula, H.C.B.d., Ulrich, C.M., Owen, R.W., 2013. Spray-drying encapsulation of mangiferin using natural polymers. Food Hydrocolloids 33, 10-18.

Sun, H., Pang, K.S., 2008. Permeability, transport, and metabolism of solutes in Caco-2 cell monolayers: a theoretical study. Drug Metab Dispos. 36, 102-123.

Takeda, T., Tsubaki, M., Kino, T., Yamagishi, M., Lida, M., Itoh, T., Imano, M., Tanabe, G., Muraoka, O., Satou, T., Nishida, S., 2016. Mangiferin induces apoptosis in multiple myeloma cell lines by suppressing the activation of nuclear factor kappa B-inducing kinase. Chem. Biol. Interact. 251, 26-33. 
Teng, H., Wu, W., 2012. Mangiferin-berberine salt, manufacturing method and use thereof. PCT/CN2010/000791.

Tran, T.H., Ramasamy, T., Truong, D.H., Choi, H.G., Yong, C.S., Kim, J.O., 2014. Preparation and characterization of fenofibrate-loaded nanostructured lipid carriers for oral bioavailability enhancement. AAPS PharmSciTech. 15, 1509-1515.

Valicherla, G.R., Dave, K.M., Syed, A.A., Riyazuddin, M., Gupta, A.P., Singh, A., Wahajuddin, Mitra, K., Datta, D., Gayen, J.R., 2016. Formulation optimization of Docetaxel loaded self-emulsifying drug delivery system to enhance bioavailability and anti-tumor activity. Sci. Rep. 6, 26895.

van der Merwe, J.D., Joubert, E., Manley, M., de Beer, D., Malherbe, C.J., Gelderblom, W.C., 2011. Mangiferin glucuronidation: important hepatic modulation of antioxidant activity. Food Chem. Toxicol. 50, 808-815.

Xia, H.J., Zhang, Z.H., Jin, X., Hu, Q., Chen, X.Y., Jia, X.B., 2013. A novel drug-phospholipid complex enriched with micelles: preparation and evaluation in vitro and in vivo. Int. J. Nanomed. 8, 545-554.

Yang, X., Zhao, Y., Chen, Y., Liao, X., Gao, C., Xiao, D., Qin, Q., Yi, D., Yang, B., 2013. Host-guest inclusion system of mangiferin with beta-cyclodextrin and its derivatives. Mater. Sci. Eng. C. Mater. Biol. Appl. 33, 2386-2391.

Yusuf, M., Sharma, V., Pathak, K., 2014. Nanovesicles for transdermal delivery of felodipine: Development, characterization, and pharmacokinetics. Int. J. Pharm. Investig. 4, 119-130.

Zakeri-Milani, P., Valizadeh, H., Tajerzadeh, H., Azarmi, Y., Islambolchilar, Z., Barzegar, S., BarzegarJalali, M., 2007. Predicting human intestinal permeability using single-pass intestinal perfusion in rat. J. Pharm. Pharm. Sci. 10, 368-379.

Zhang, B.F., Jun; Chen, Yan, 2013. Antioxidant Effect of Mangiferin and its Potential to be a Cancer Chemoprevention Agent. Lett Drug Des Discov. 10,, 239-244.

Zhao, Y., Wang, L., Ma, C., Zhao, K., Liu, Y., Feng, N., 2013. Preparation and characterization of tetrandrine-phospholipid complex loaded lipid nanocapsules as potential oral carriers. Int J Nanomedicine 8, 4169-4181.

Zheng, M.S., Lu, Z.Y., 1990. Antiviral effect of mangiferin and isomangiferin on herpes simplex virus. Chin. Med. J (Engl). 103, 160-165.

\section{Figures:}




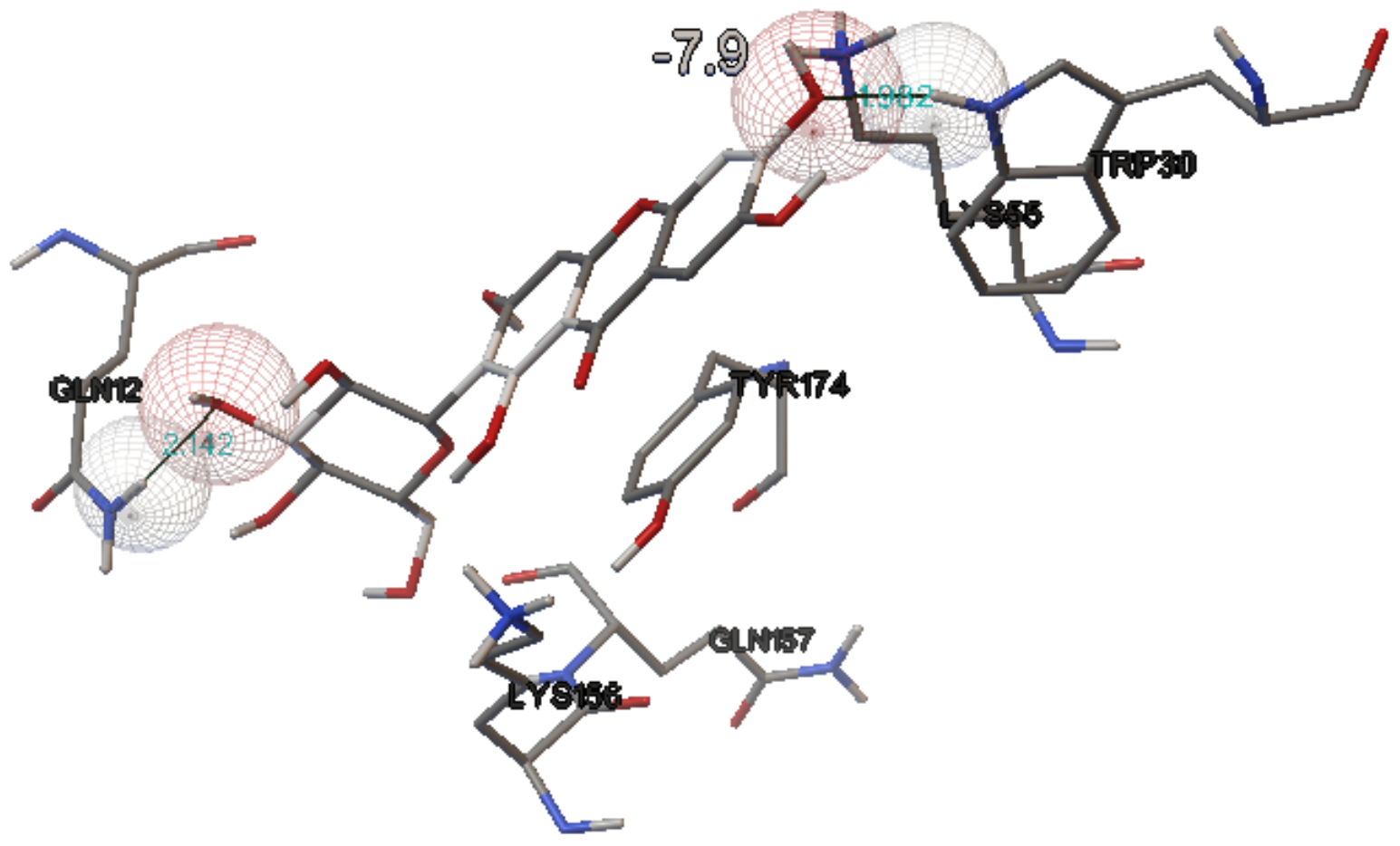

Figure 1: Molecular docking images depicting binding of mangiferin with phosphatidylcholine transfer protein 

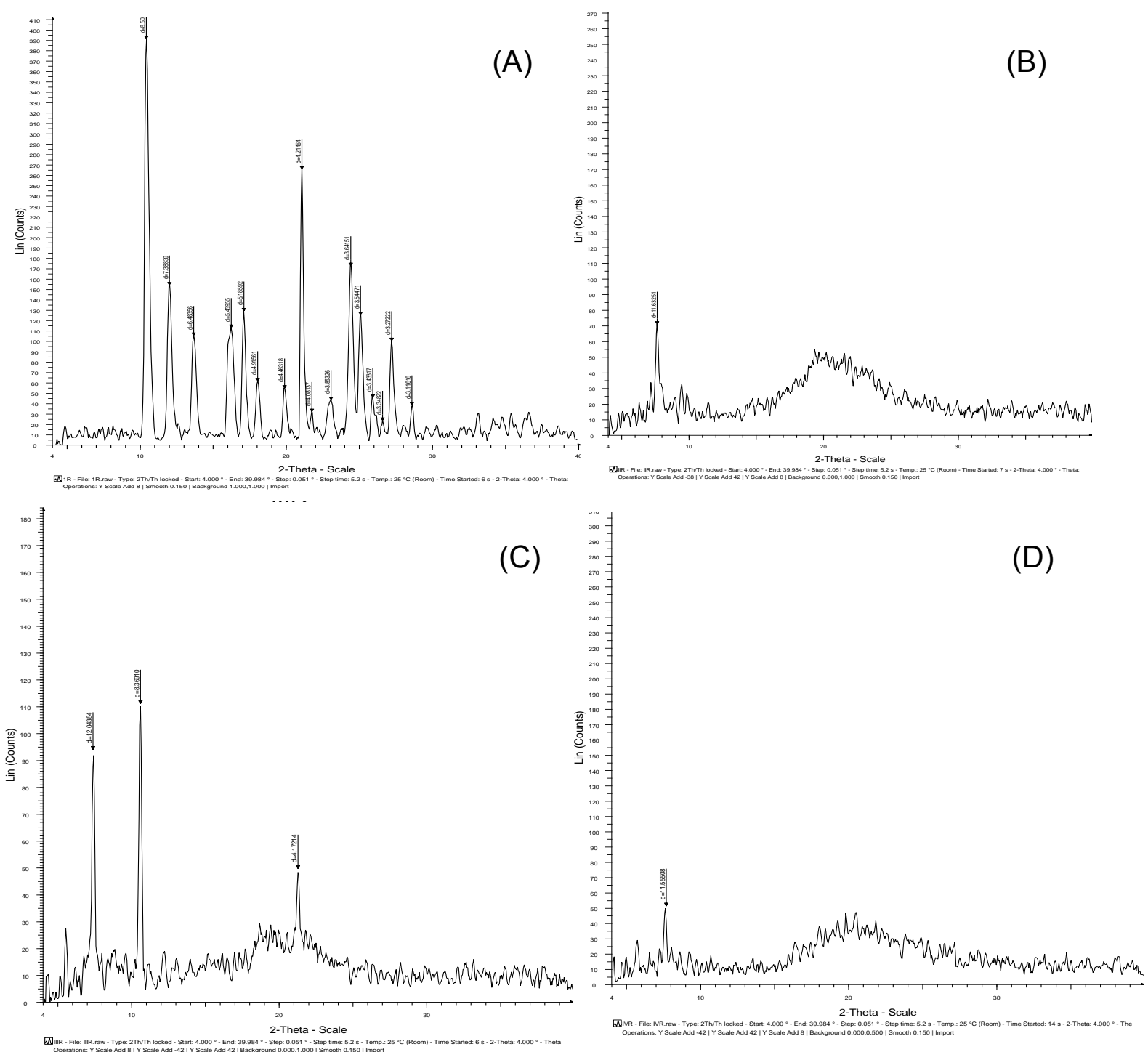

Figure 2: X-ray diffraction patterns of (A) mangiferin; (B) Phospholipon 90 G; (C); physical mixture of mangiferin and Phospholipon $90 \mathrm{G}$ (D) mangiferinPhospholipon 90 G complex 

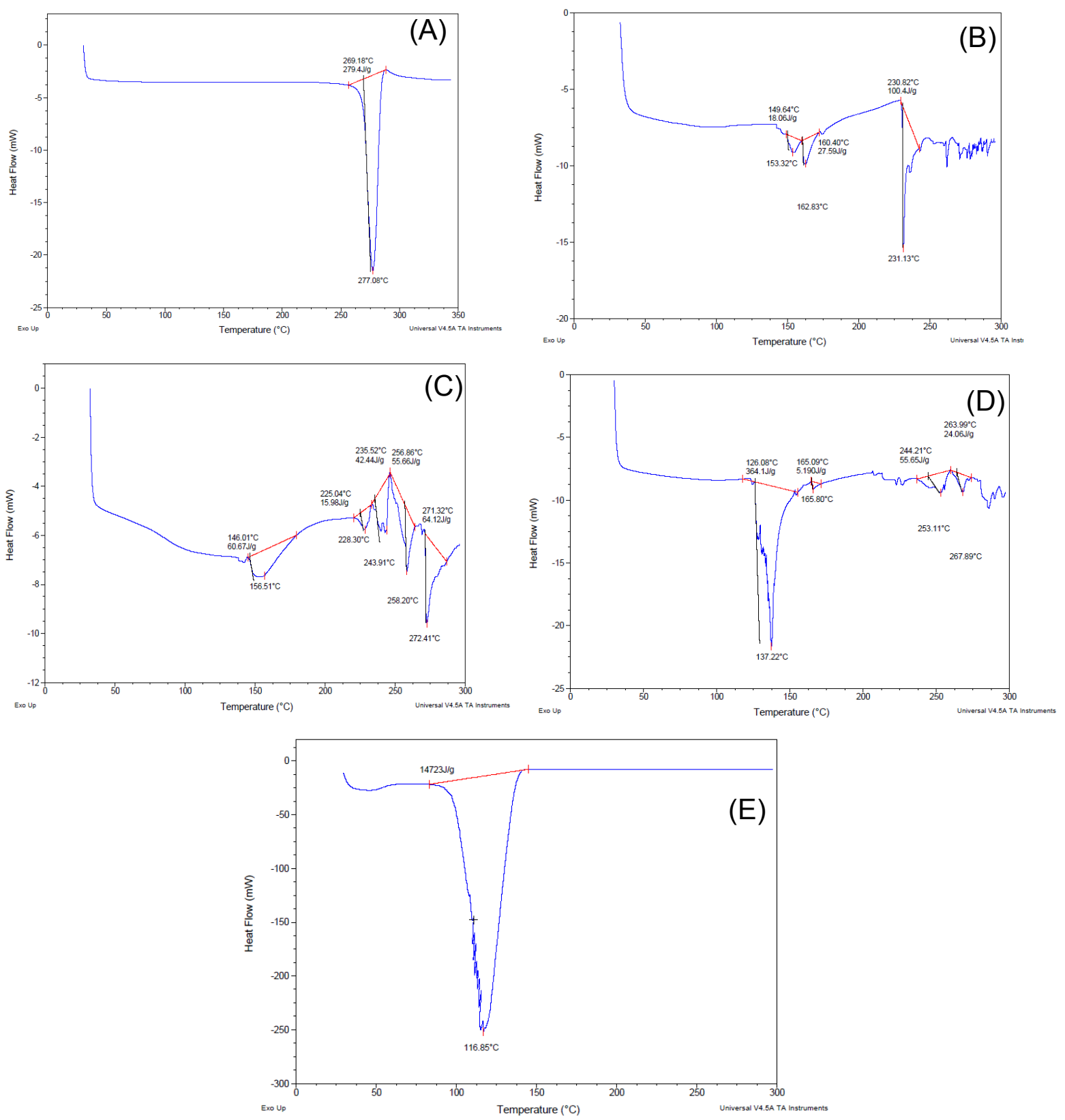

Figure 3: DSC thermograms of (A) mangiferin; (B) Phospholipon 90G; (C); physical mixture of mangiferin and Phospholipon 90G (D) Mangiferin-Phospholipon-90G complex (E) Complex loaded nanostructured lipidic systems 


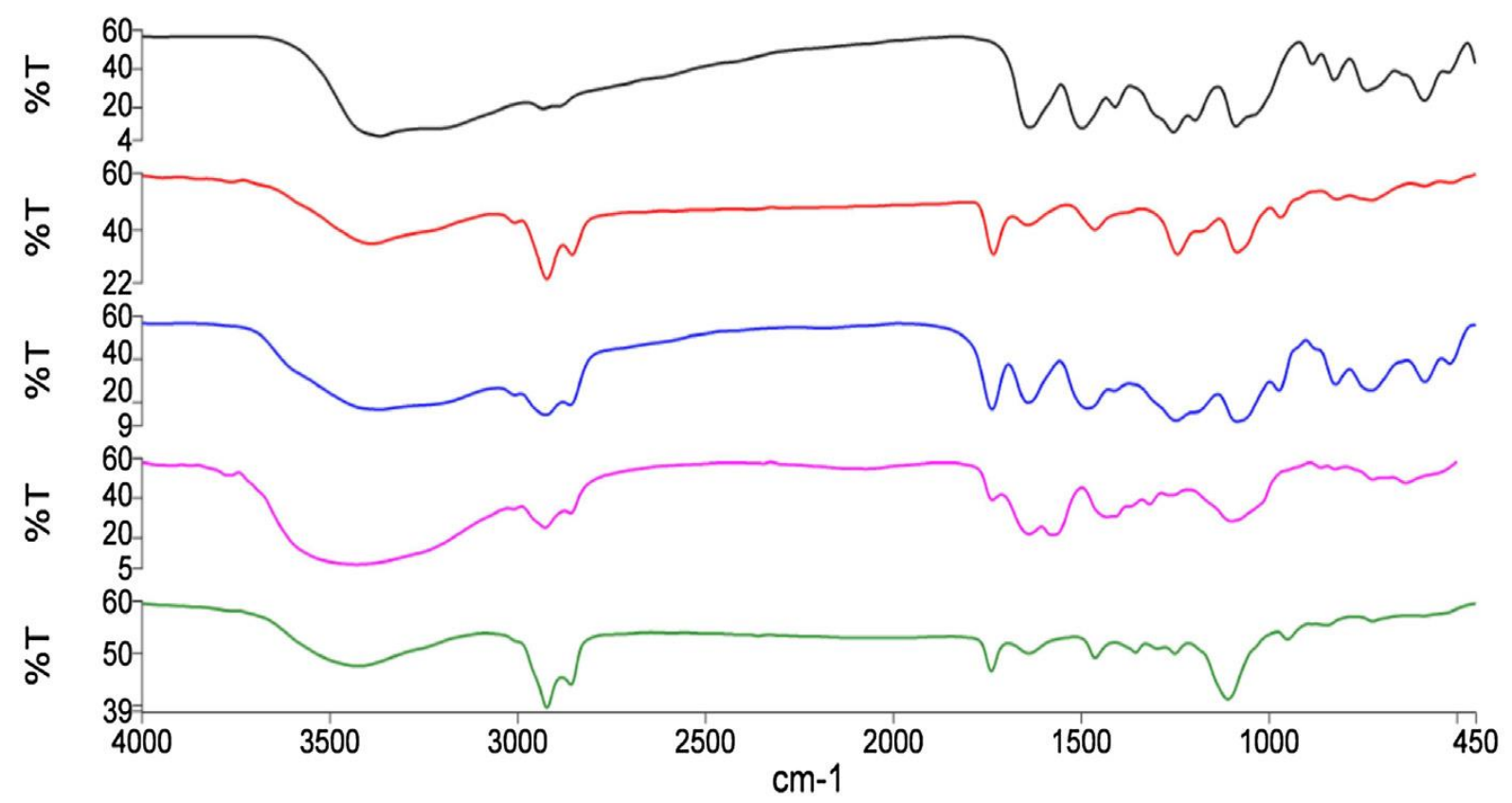

Figure 4: FTIR spectra of (A) mangiferin; (B) Phospholipon 90G; (C); Physical mixture of mangiferin and Phospholipon 90G (D) mangiferin Phospholipon 90G complex (E) Complex loaded nanostructured lipidic systems 


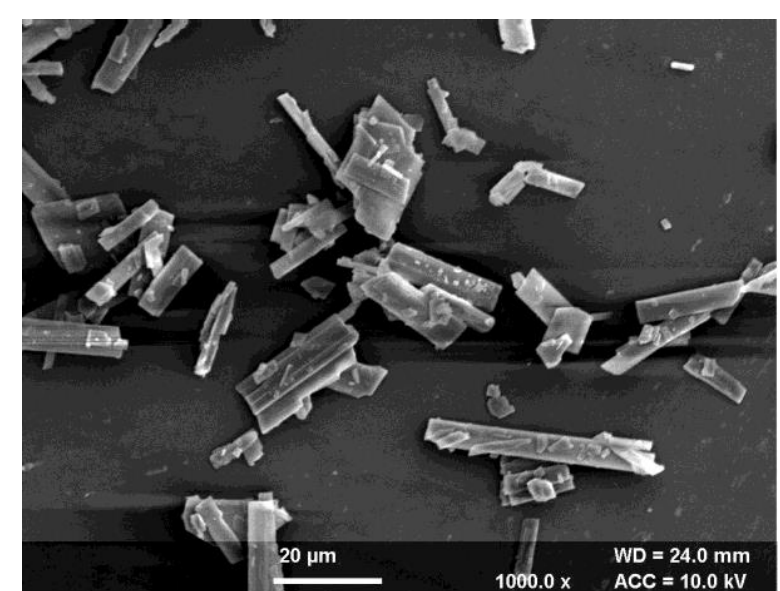

A

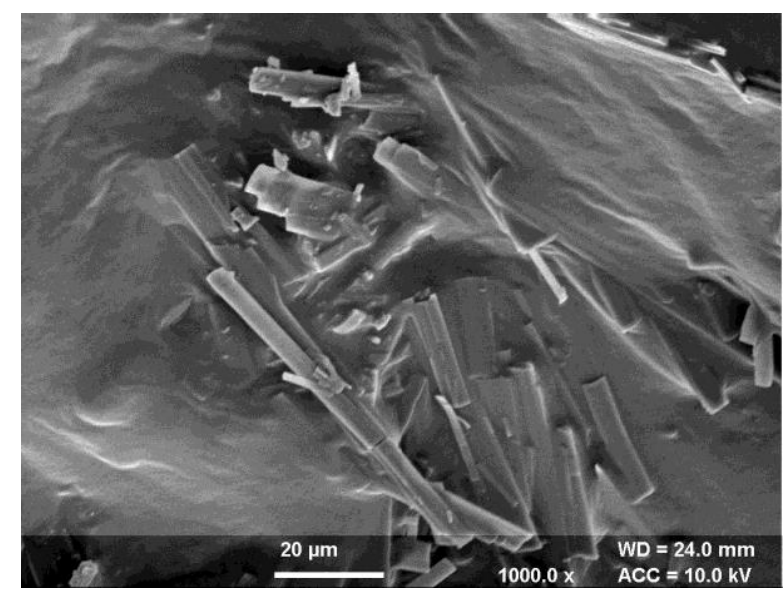

C

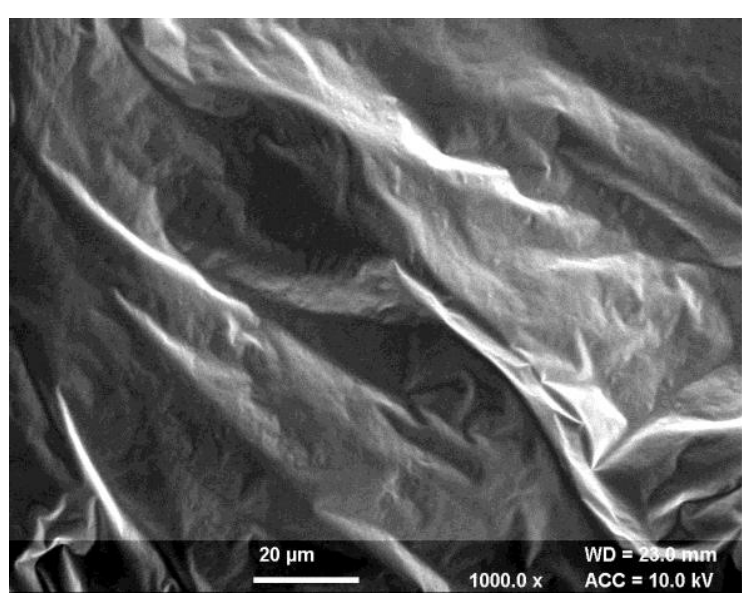

B

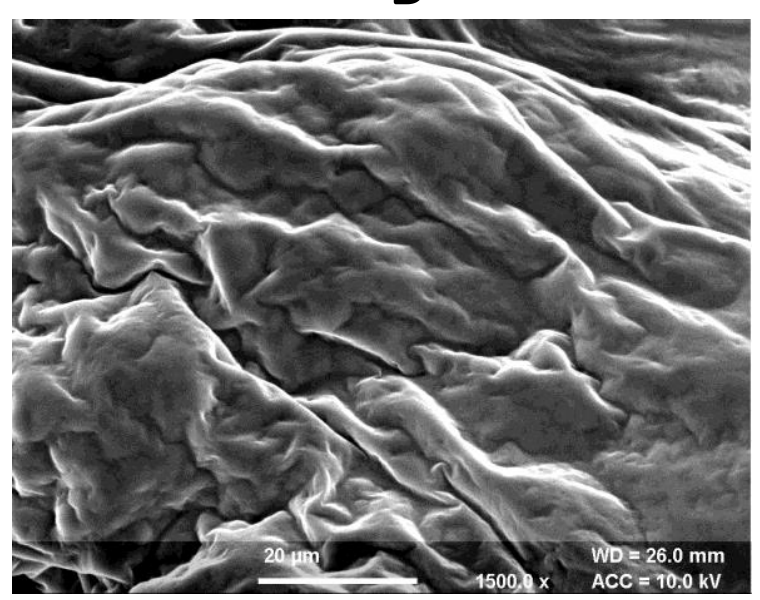

D

Figure 5: Scanning electron microscopic pictures of (A) mangiferin, (B) Phospholipon 90G, (C) Physical mixture of mangiferin and Phospholipon 90G (D) mangiferin-Phospholipon 90G complex 


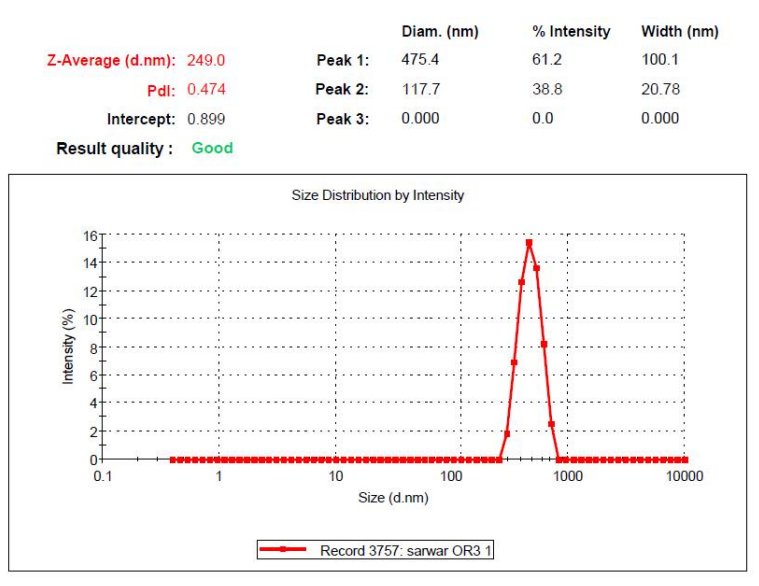

(A)

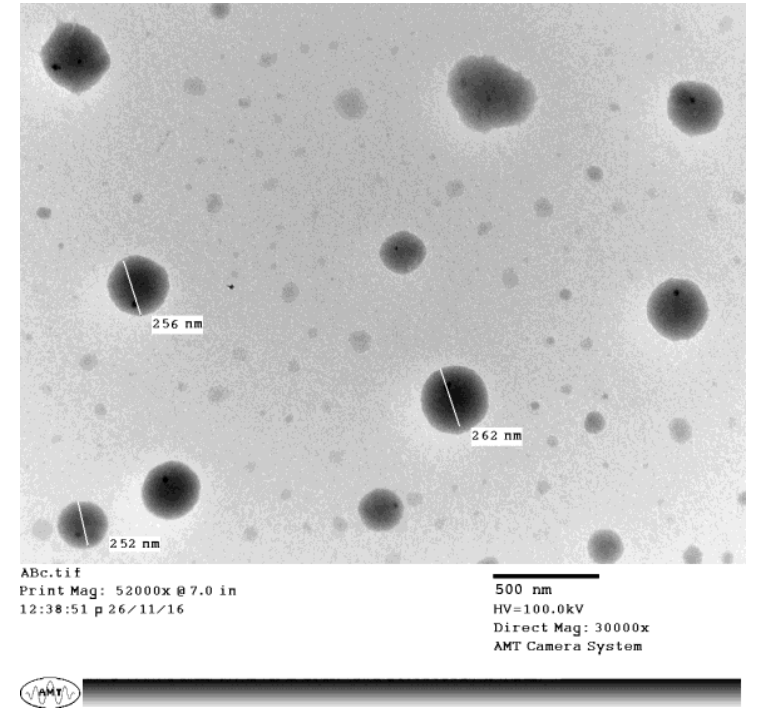

(B)

Figure 6: Morphological analysis of optimized PLCs-NLCs (A) particle size (B) TEM

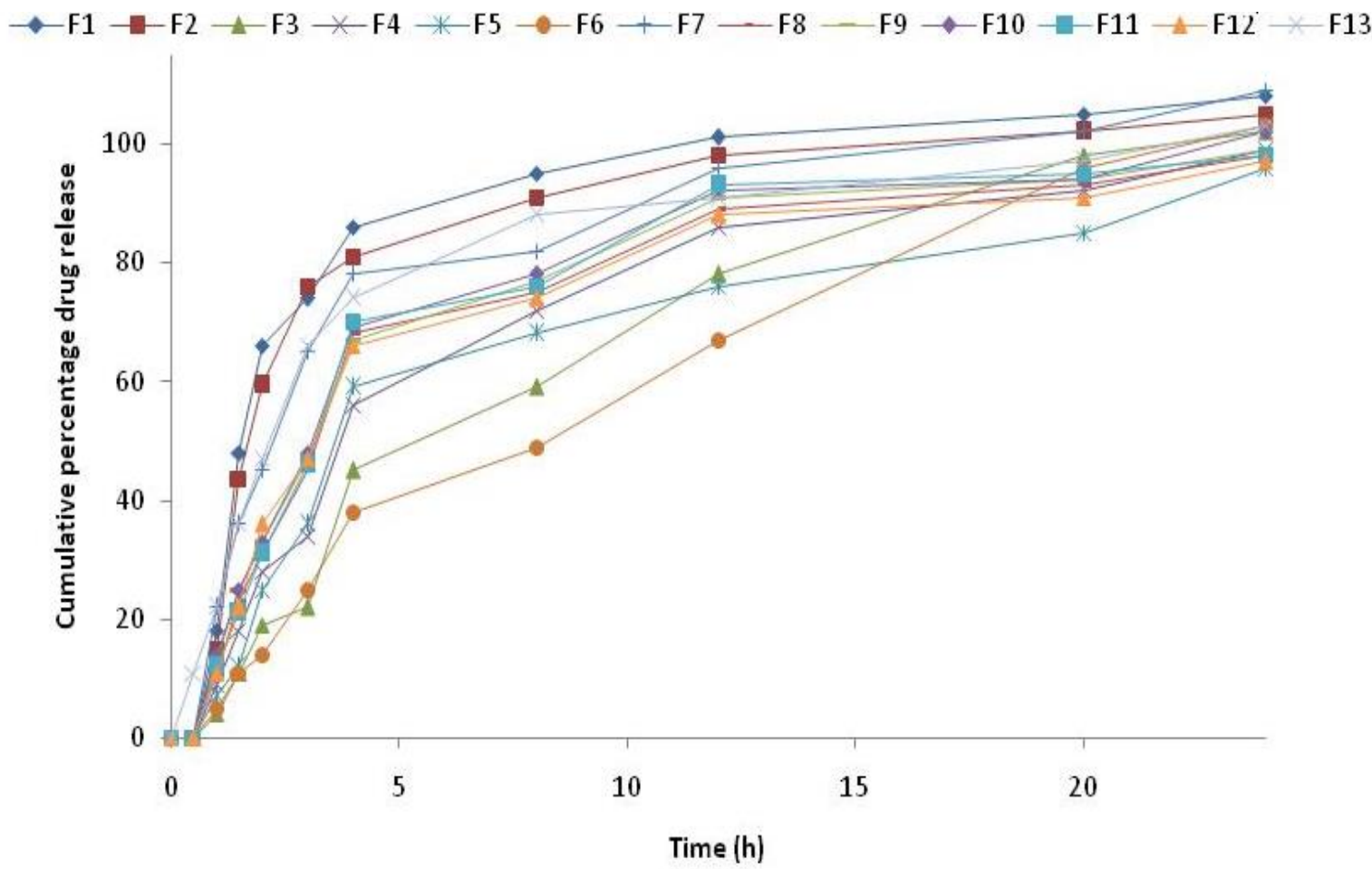

Figure 7: Mean percent drug release of mangiferin from various PLCs-NLCs formulations, prepared as per the experimental design. 


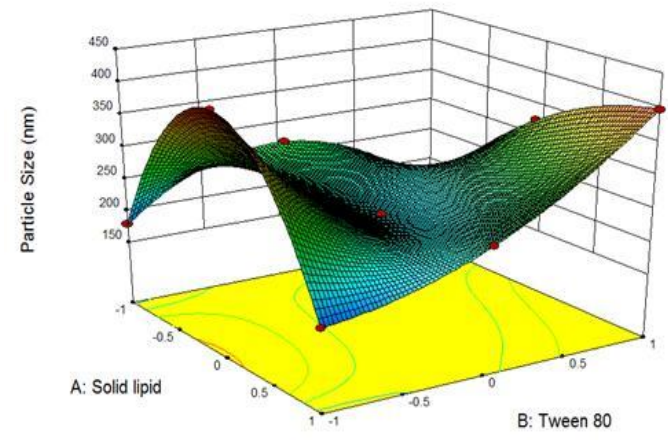

(A)

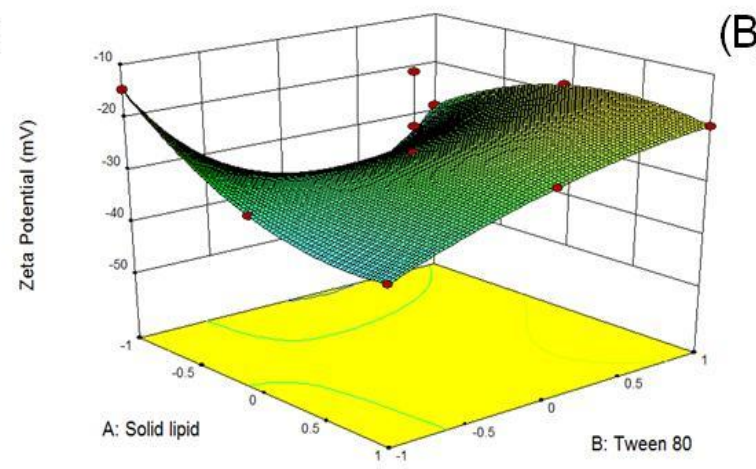

(B)

(C)

(D)
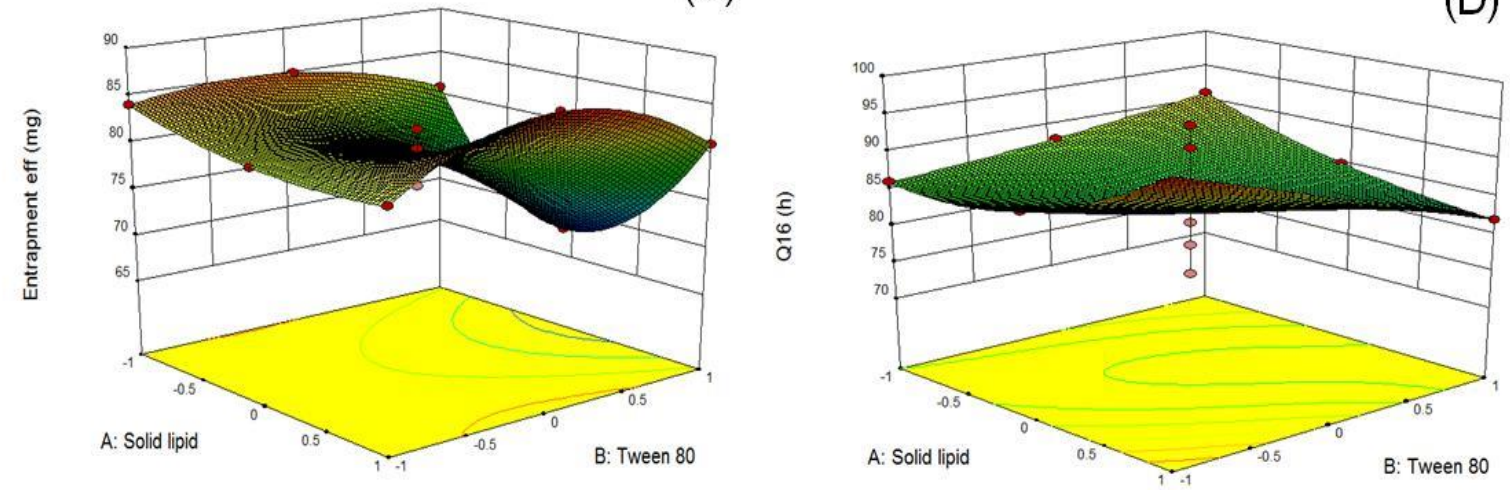

Figure 8: 3D-Response surface plots showing the influence of ratio of solid: liquid lipids and Tween 80 on (A) Particle size (B) Zeta potential (C) Entrapment efficiency (D) Q16. 


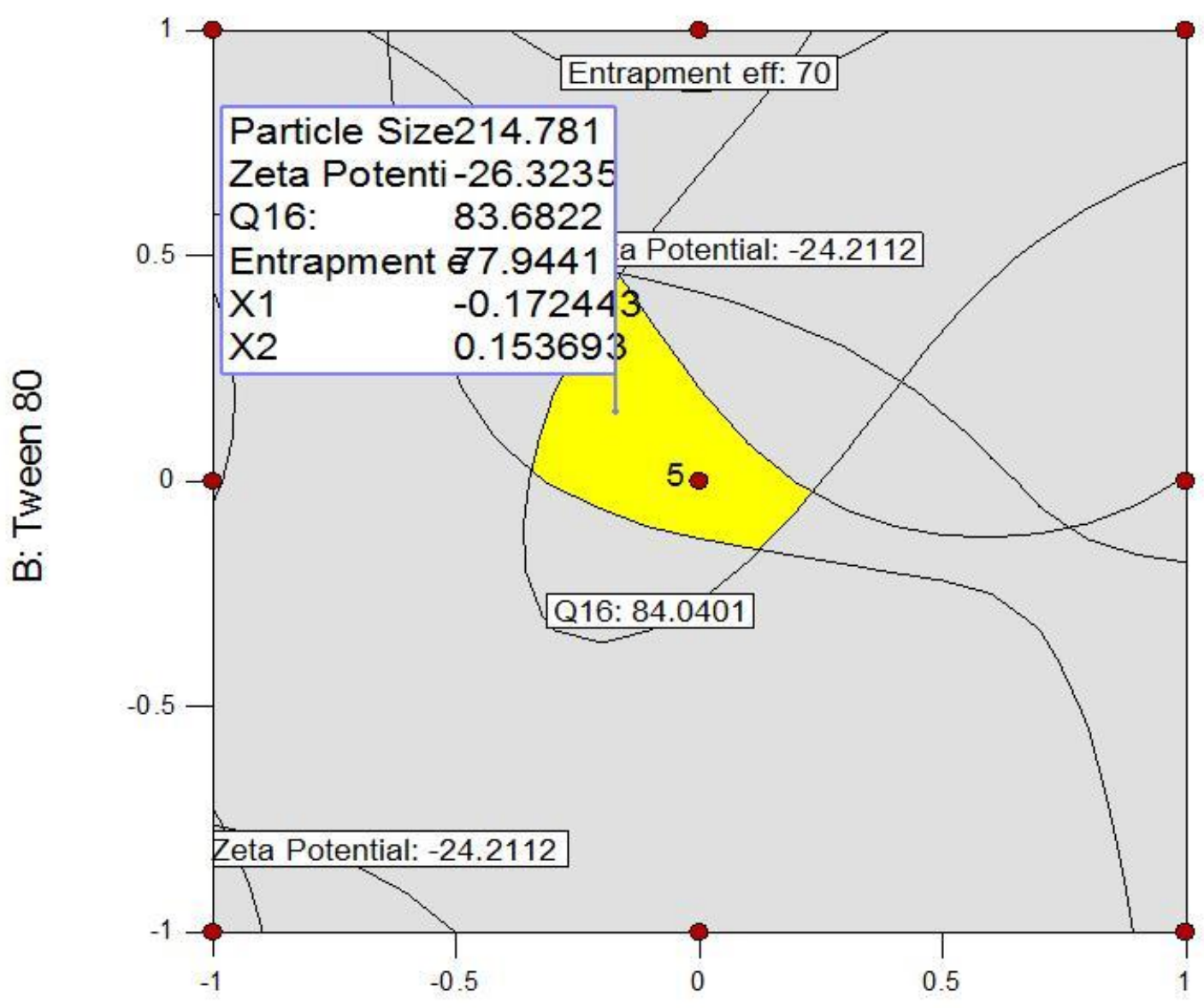

A: Solid lipid

Figure 9: Overlay plot depicting the design space region and optimized NLCs formulation of mangiferin (flagged).

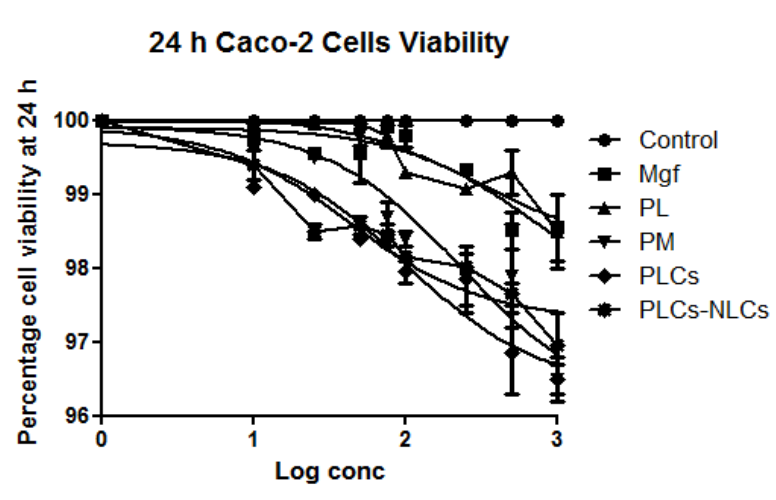

(A)

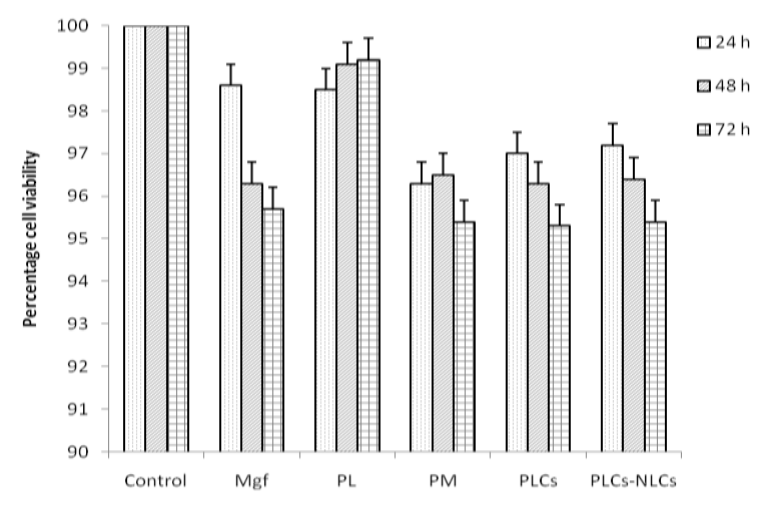

(B)

Figure 10: Bar graphs depicting the Caco-2 cell viability scores with all the treatment formulations viz. Mgf: mangiferin; PL: Phospholipon 90G; PM: physical 
mixture of Mgf and PL; PLCs: Mangiferin:Phospholipon 90G mixture; PLCs-NLCs: PLCs-nanostructured lipidic systems at $24 \mathrm{~h}, 48 \mathrm{~h}, 72 \mathrm{~h}$ (Mean $(\mathrm{n}=3) \pm \mathrm{SD})$

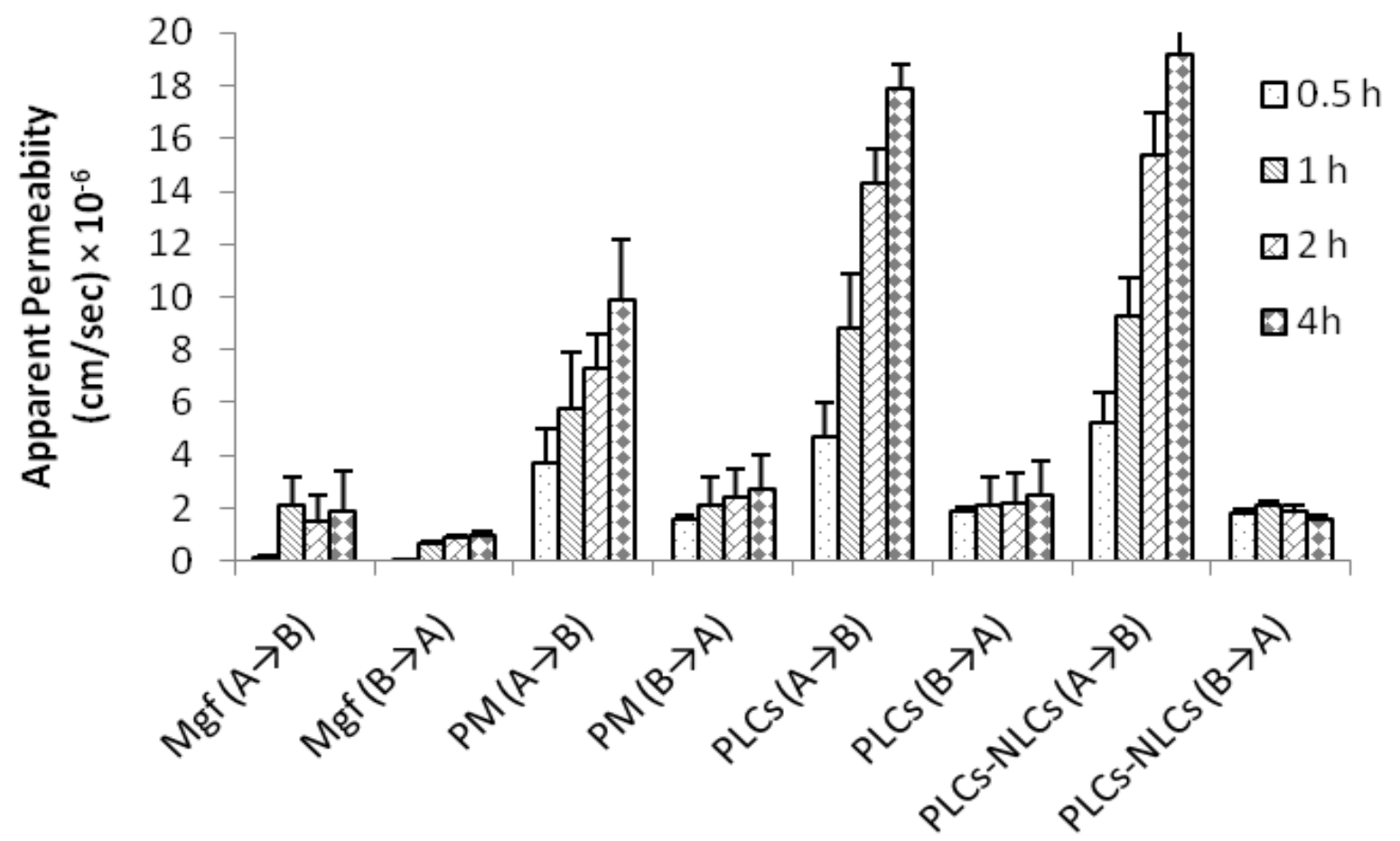

Figure 11: Bidirectional permeation study of various treatment of Mgf (mangiferin), PM (physical mixture), PLCs (mangiferin-Phospholipon 90G complex) and PLCs-NLCs (PLCs-nanostructured lipidic systems) on Caco-2 cells; value expressed in mean $\pm S D(n=3)$ 
Histograms
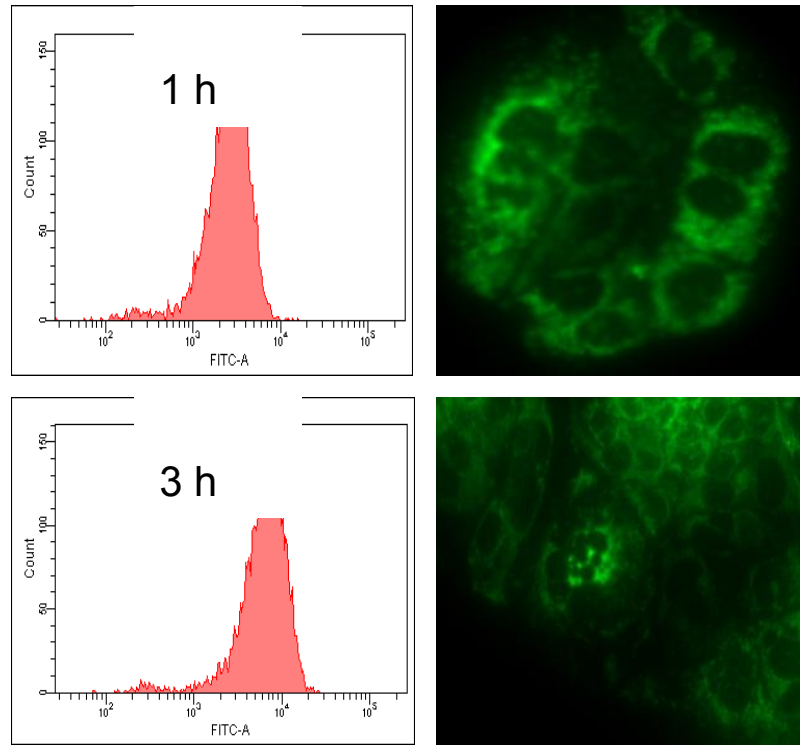

Caco-2 cells

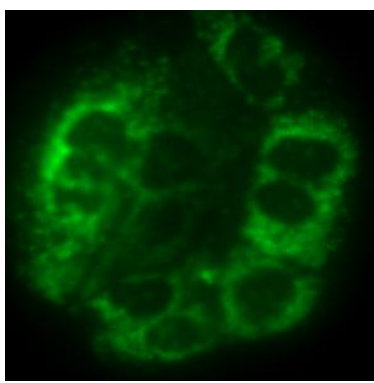

Rh-123 stained

(B)

Nucleus stained with DAPI
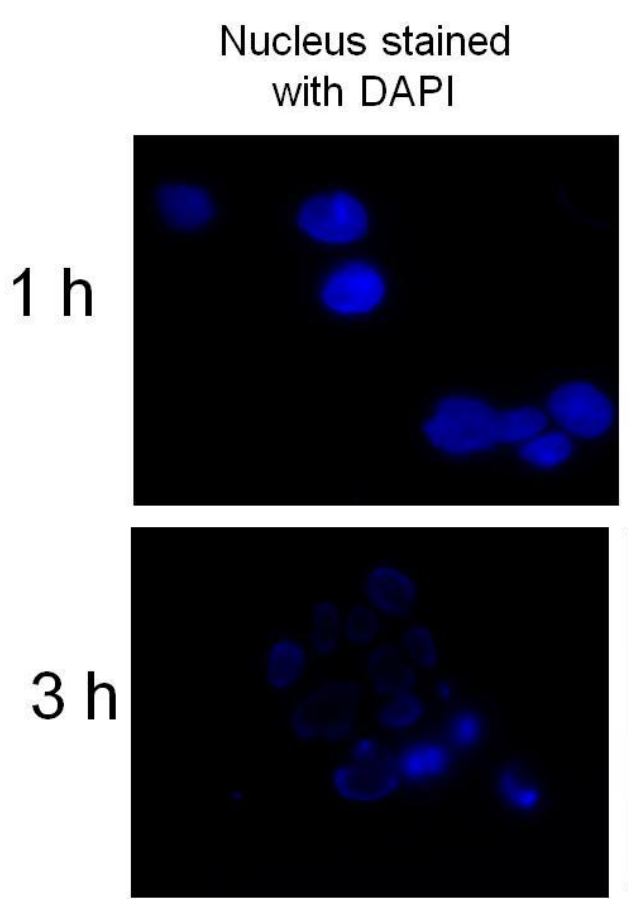

Rh-123 stained

Caco-2cells
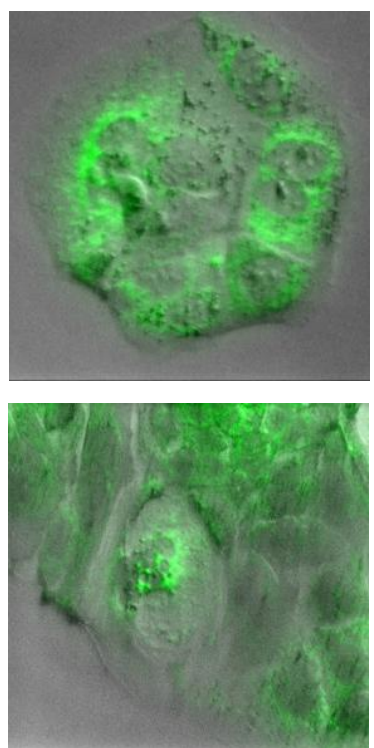

DIC images of

Caco-2cells
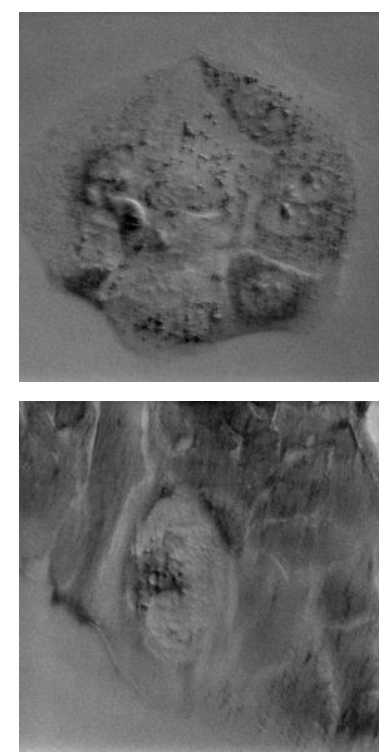

Rh-123 stained

Caco-2 cells
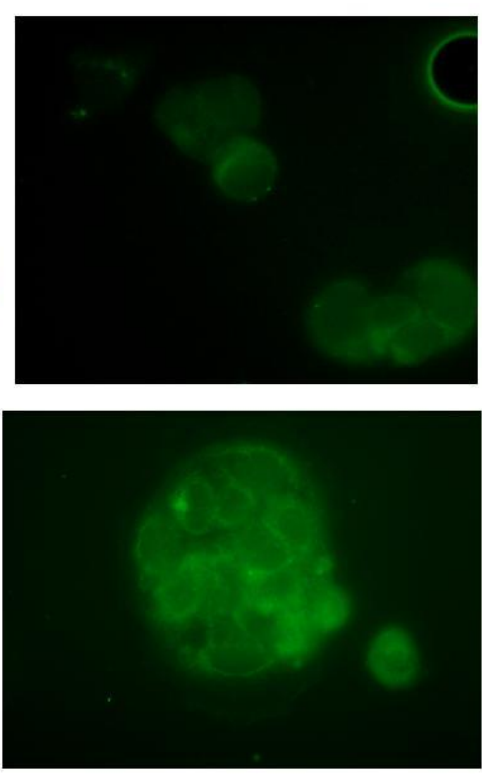

Merged image of

Caco-2 cells
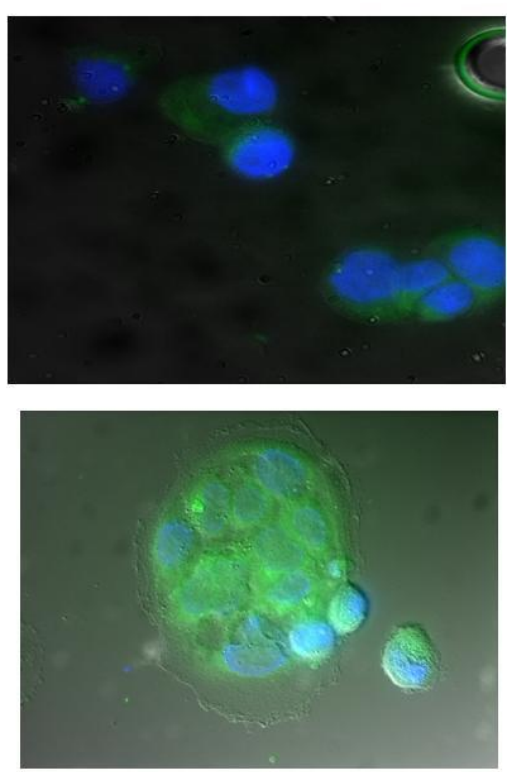

Figure 12: (A) Histograms and fluoescent images observed at $1 \mathrm{~h}$ and $3 \mathrm{~h}$ for Rh-123 loaded NLCs on Caco-2 cells (B) DAPI (Blue fluorscence) indicates the staining of nucleus while Rh-123 (green fluorscence) displays the uptake of NLCs at $1 \mathrm{~h}$ and 3 h. 


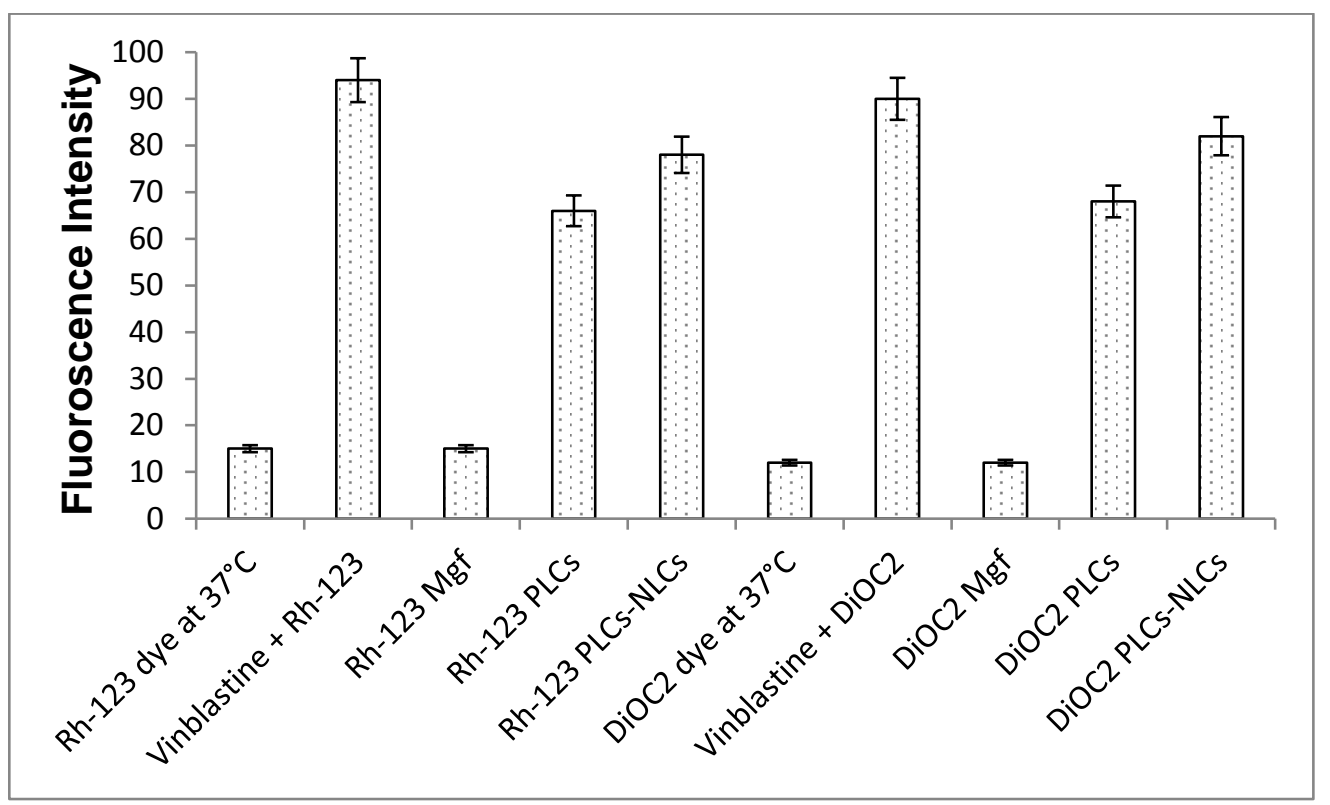

Figure 13: Fluorescence index indicates the inhibition of the MDRI transporters for Rh-123-loaded formulations and BCRP transporters for DiOC2-loaded formulations. Each cross bar indicates $\pm S D(n=3)$.

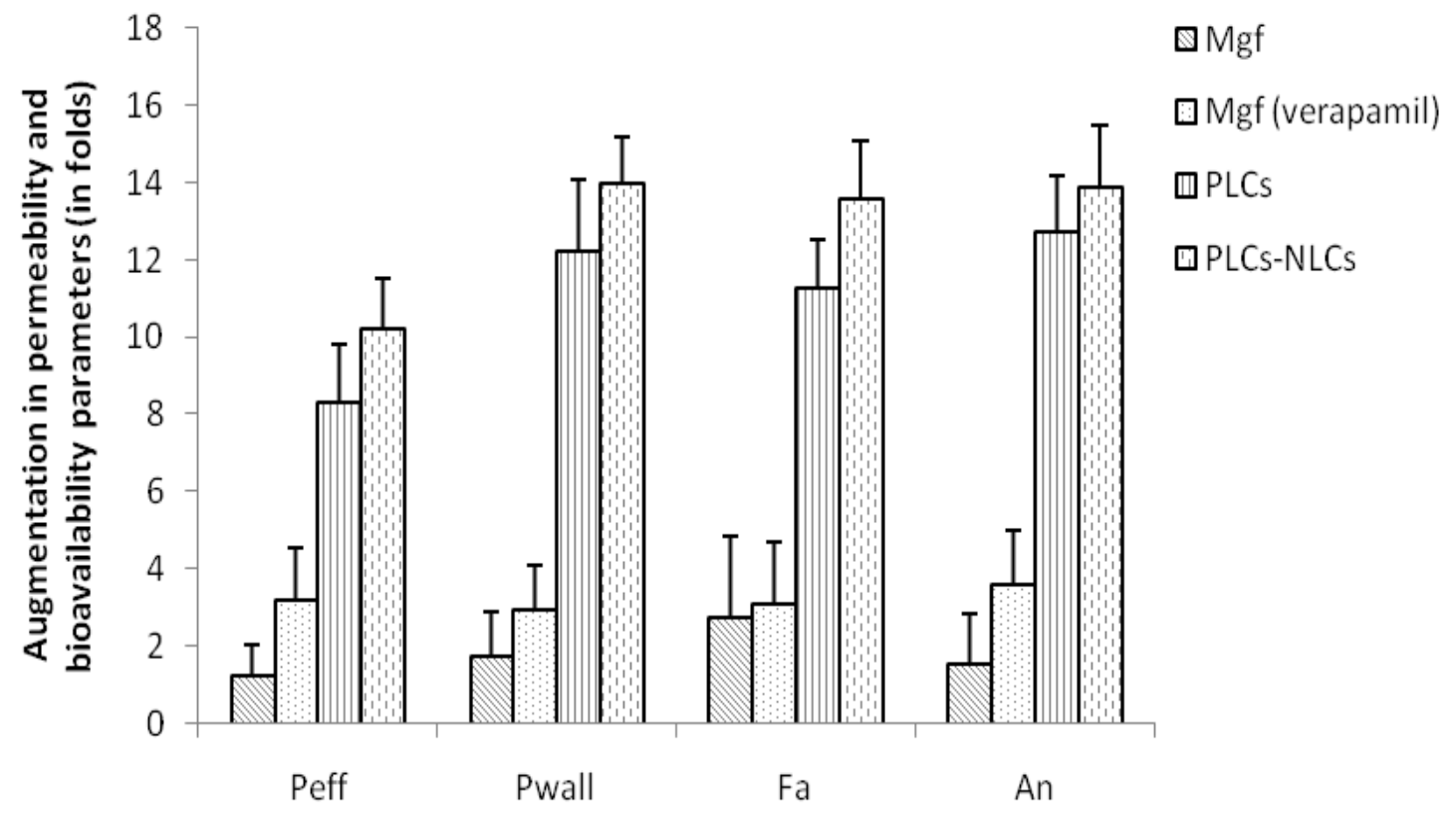

Figure 14: Increase in permeability and absorption paramaeters (in folds) of PLCsNLCs vis-a-vis Mgf, with and without verapamil across the rat intestine. Each cross 
bar indicates $+1 S D ; P_{\text {eff: }}$ effective permeability; $P_{\text {wall: }}$ wall permeability; $F_{a}$ : fraction of dose absorbed; $A_{n}$ : absorption number

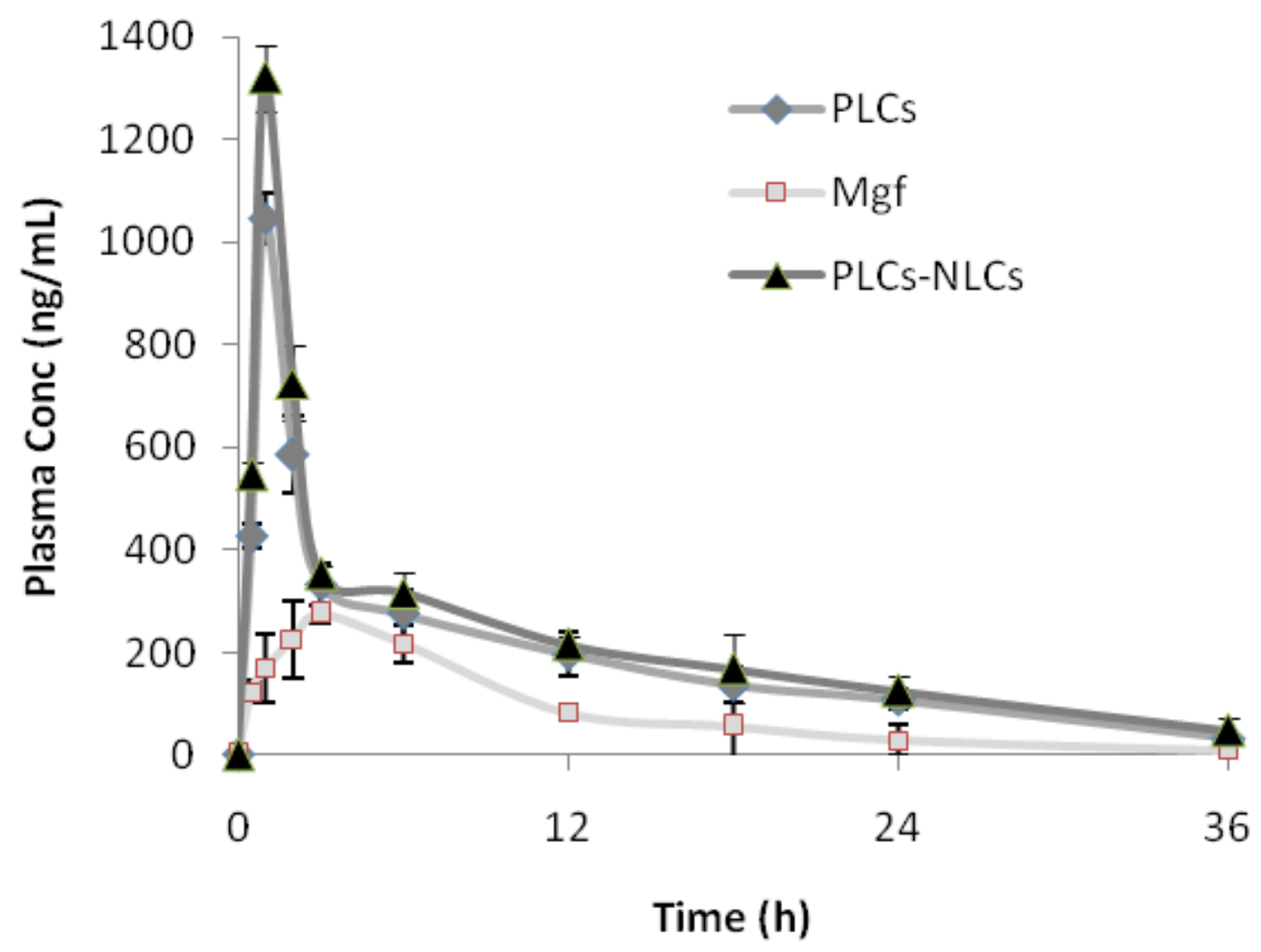

Figure 15: Mean plasma concentration-time curve of Mangiferin and Mangiferin-Phospholipon $90 \mathrm{G}$ complex equivalent to $30 \mathrm{mg} / \mathrm{mL} \quad(\mathrm{n}=6)$, respectively; mean value of \pm SD (LOQ obtained for the method in plasma is 36.55 $\mathrm{ng} / \mathrm{mL})$.

Supplementary Table 1: QTPP elements for NLCs of Mgf

\begin{tabular}{|c|c|l|}
\hline TPP Elements & Target & \multicolumn{1}{|c|}{ Justification } \\
\hline Dosage form & NLCs & $\begin{array}{l}\text { Selection of the nanostructured lipid- } \\
\text { based system helps in augmenting the } \\
\text { oral bioavailability }\end{array}$ \\
\hline Dosage type & $\begin{array}{c}\text { Sustained } \\
\text { release }\end{array}$ & $\begin{array}{l}\text { Slower and sustained release } \\
\text { characteristics help in superior drug } \\
\text { absorption potential }\end{array}$ \\
\hline Dosage strength & $30 \mathrm{mg}$ & $\begin{array}{l}\text { Unit dose of the drug recommended } \\
\text { for the management of cancer }\end{array}$ \\
\hline $\begin{array}{c}\text { Route of } \\
\text { administration }\end{array}$ & Oral & $\begin{array}{l}\text { Recommended route for delivery of } \\
\text { Mgf to act as antioxidant }\end{array}$ \\
\hline
\end{tabular}




\begin{tabular}{|c|c|l|}
\hline Pharmacokinetics & $\begin{array}{c}\text { Higher } \mathrm{C}_{\max } \text { and } \\
\text { AUC, and } \\
\text { extended } t_{\max }\end{array}$ & $\begin{array}{l}\text { Required for achieving higher drug } \\
\text { levels into the systemic circulation } \\
\text { with enhanced therapeutic action for } \\
\text { prolonged period of time }\end{array}$ \\
\hline Stability & $\begin{array}{c}\text { At least } 24 \\
\text { months at room } \\
\text { temperature }\end{array}$ & $\begin{array}{l}\text { To maintain therapeutic potential of } \\
\text { the drug during storage period }\end{array}$ \\
\hline
\end{tabular}

Supplementary Table 2: CQAs for the NLCs of Mgf and justifications for them

\begin{tabular}{|c|c|c|l|}
\hline CQAs & Target & $\begin{array}{c}\text { Is this } \\
\text { a CQA? }\end{array}$ & \multicolumn{1}{|c|}{ Justification(s) } \\
\hline $\begin{array}{c}\text { Particle size } \\
(\mathrm{nm})\end{array}$ & $<100 \mathrm{~nm}$ & Yes & $\begin{array}{l}\text { Smaller globule size allows } \\
\text { easy penetration of NLCs } \\
\text { through gastrointestinal } \\
\text { epithelial lining and } \\
\text { paracellular pathways; hence } \\
\text { was regarded as highly critical. }\end{array}$ \\
\hline $\begin{array}{c}\text { Zeta potential } \\
(\mathrm{mV})\end{array}$ & $>-15 \mathrm{mV}$ & Yes & $\begin{array}{l}\text { Optimum value of zeta } \\
\text { potential in positive and or } \\
\text { negative sign is desired for } \\
\text { maintaining stability of the } \\
\text { system, thus considered as } \\
\text { critical. }\end{array}$ \\
\hline $\begin{array}{c}\text { Entrapment } \\
\text { efficiency }\end{array}$ & $>80 \%$ & Yes & $\begin{array}{l}\text { Higher value of entrapment } \\
\text { efficiency is desirable for } \\
\text { attaining maximal therapeutic } \\
\text { response. Hence, it was } \\
\text { considered to be highly critical. }\end{array}$ \\
\hline $\begin{array}{c}\text { Time required for } \\
80 \% \text { drug release }\end{array}$ & $>10-12 \mathrm{~h}$ & Yes & $\begin{array}{l}\text { Sustained release characteristic } \\
\text { is desired for attaining } \\
\text { prolonged drug absorption, } \\
\text { hence considered critical for } \\
\text { the purpose. }\end{array}$ \\
\hline
\end{tabular}




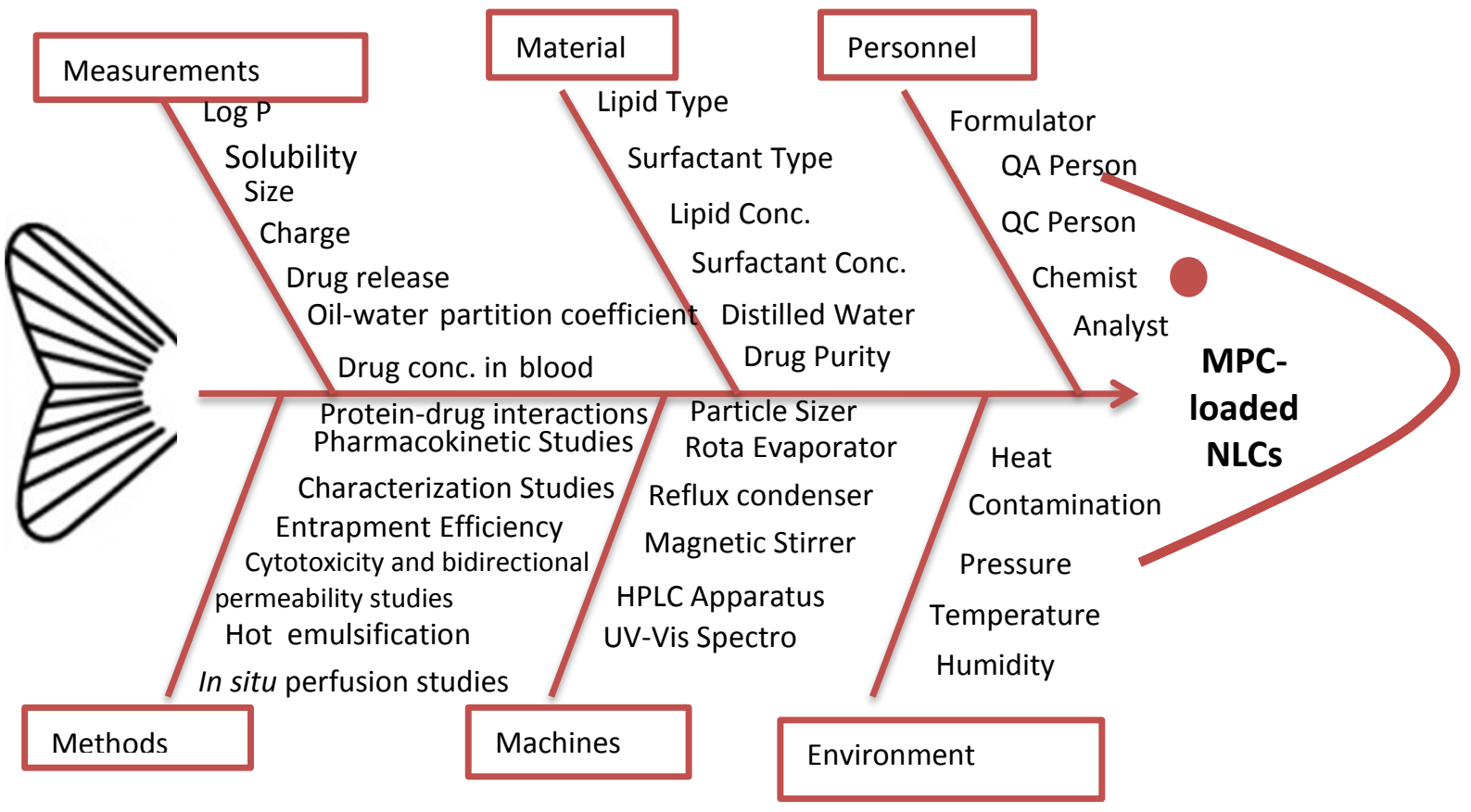

Supplementary Figure 1: Ishikawa fish bone diagram 
Supplementary Table 3: Initial risk assessment for MPC-loaded NLCs

\begin{tabular}{|c|c|c|c|c|c|c|c|c|c|c|}
\hline \multirow[b]{2}{*}{ CQAs } & \multicolumn{10}{|c|}{ RISK ESTIMATION MATRIX } \\
\hline & $\begin{array}{c}\text { API } \\
\text { particle } \\
\text { size }\end{array}$ & $\begin{array}{c}\text { Type of } \\
\text { phospholipid }\end{array}$ & $\begin{array}{c}\text { Type of } \\
\text { surfactant }\end{array}$ & $\begin{array}{l}\text { Amount } \\
\text { of solid } \\
\text { lipid }\end{array}$ & $\begin{array}{c}\text { Amount } \\
\text { of } \\
\text { emulgent }\end{array}$ & $\begin{array}{l}\text { Reflux } \\
\text { temperature } \\
\text { and time }\end{array}$ & $\begin{array}{l}\text { Ultrasonication } \\
\text { time and cycles }\end{array}$ & $\begin{array}{l}\text { Type of } \\
\text { Stirring }\end{array}$ & $\begin{array}{c}\text { Stirring } \\
\text { speed and } \\
\text { time }\end{array}$ & $\begin{array}{c}\text { Homogeniser } \\
\text { speed and } \\
\text { time }\end{array}$ \\
\hline Assay & Low & Low & Low & Low & Low & Low & Low & Low & Low & Low \\
\hline $\begin{array}{l}\text { Particle size } \\
\text { (nm) }\end{array}$ & Low & Low & Low & High & High & Medium & Medium & Low & Medium & Medium \\
\hline $\begin{array}{l}\text { Zeta potential } \\
\qquad(\mathrm{mV})\end{array}$ & Low & Low & Low & High & High & Medium & Medium & Low & Medium & Medium \\
\hline $\begin{array}{c}\text { Encapsulation } \\
\text { efficiency } \\
\text { (mg) }\end{array}$ & Low & Medium & Low & High & High & Medium & Medium & Low & Medium & Medium \\
\hline $\begin{array}{l}\text { In vitro drug } \\
\text { release }\left(Q_{16}\right)\end{array}$ & Low & Low & Low & High & High & Low & Low & Low & Low & Low \\
\hline
\end{tabular}

High risk parameter

Medium risk parameter

Low risk parameter 
Supplementary Table 4: Optimization studies enlisting the CMAs of NLCs for their respective low and high levels for employing FCCD

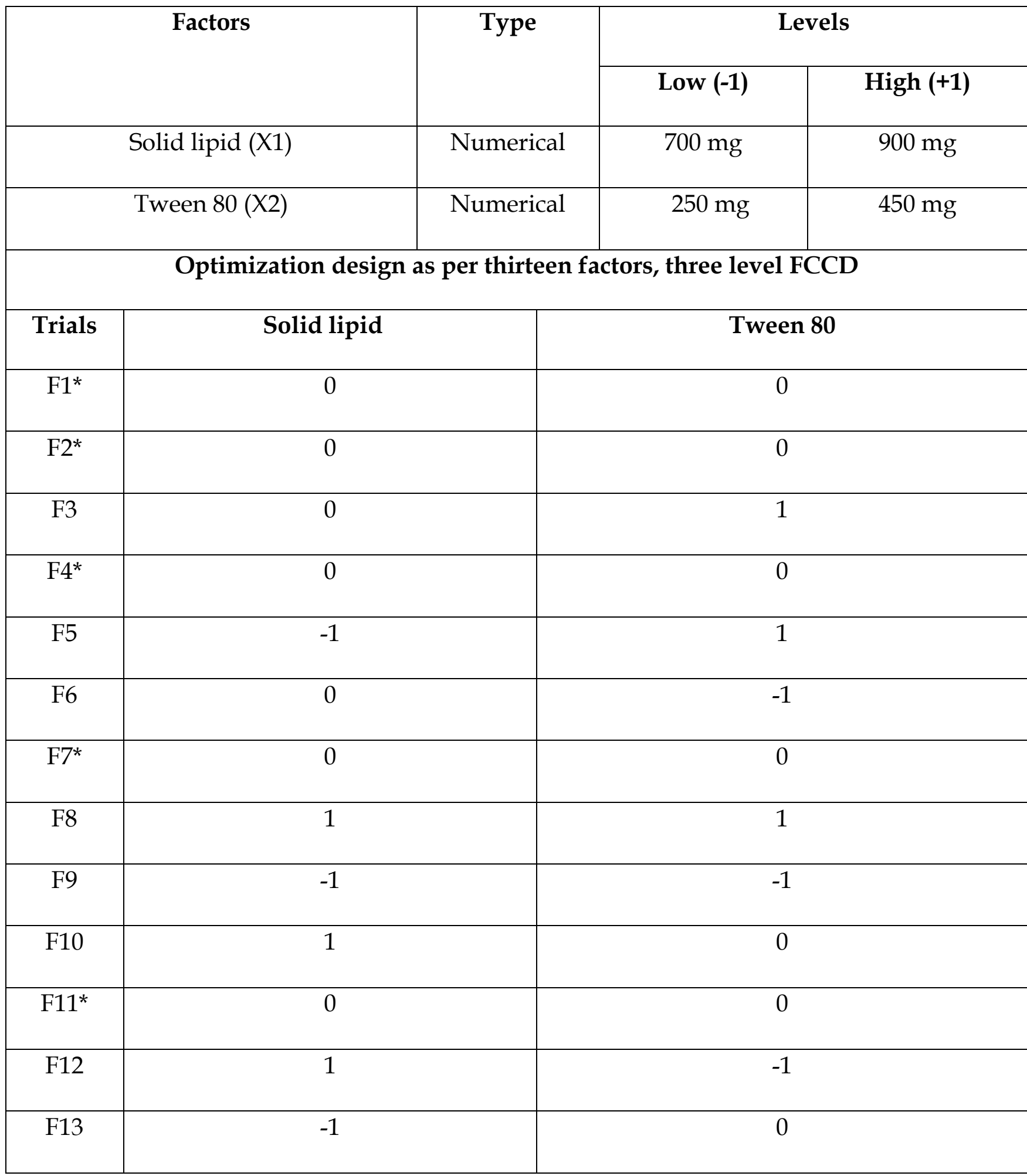


Supplementary Table 5: Linear regression data for calibration curve of mangiferin in human plasma $(n=3)$

\begin{tabular}{cc} 
Parameters & Values \\
\hline Linearity range (ng/band) & $50-1000$ \\
Regressed equation & $\mathrm{Y}=3.038 \mathrm{x}+1062$ \\
Correlation coefficient & $0.997 \pm 0.0010$ \\
Slope \pm SD & $3.04 \pm 0.557$ \\
LOD & $12.01 \mathrm{ng} / \mathrm{mL}$ \\
LOQ & $36.46 \mathrm{ng} / \mathrm{mL}$ \\
\hline
\end{tabular}

